\title{
Transplant Tourism and the Traveling Transplant Recipient: Infection Mitigation and Treatment Strategies
}

\author{
C. Arianne Buchan
}

\section{Contents}

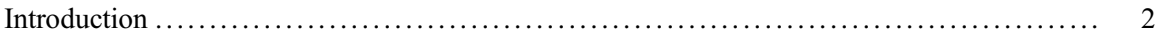

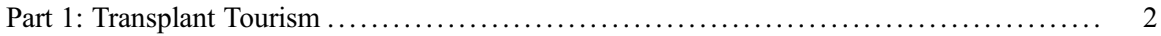

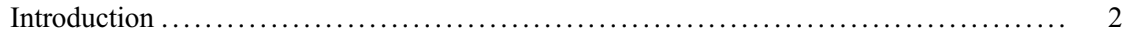

Transplant Tourism and Infectious Complications .............................. 3

Conclusion ......................................................... 5

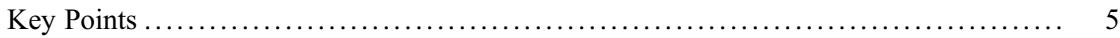

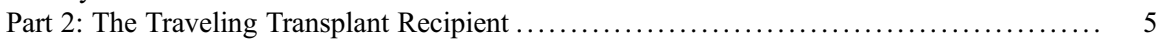

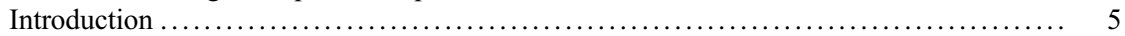

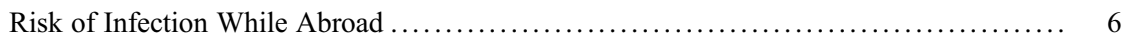

Pre-departure Infectious Disease Evaluation and Recommendations ................. 22

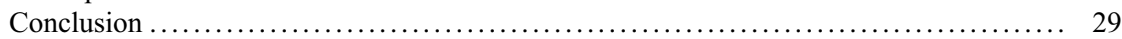

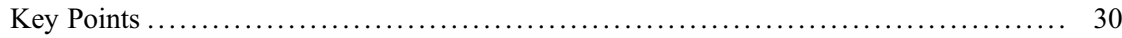

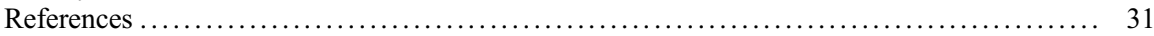

\begin{abstract}
Transplant tourism and travel posttransplant, both solid organ and hematopoietic stem cell, are important and distinct topics, and each poses a risk of infection for transplant recipients. As solid organ transplant becomes a more common treatment option for end-stage organ disease, wait lists and wait times for these organs grow. Transplant tourism involves traveling abroad for the purposes of organ transplant and often involves commercial transactions. This process has been discouraged on ethical grounds and is illegal in many countries, however it still occurs. Patients may also travel abroad for stem cell therapies, which include
\end{abstract}

C. A. Buchan $(\bowtie)$

Divisoin of Infectious Diseases, Department of Medicine, The Ottawa Hospital, Ottawa, ON, Canada

The University of Ottawa, Ottawa, ON, Canada

The Ottawa Hospital Research Institute, Ottawa, ON, Canada e-mail: abuchan@toh.ca 
experimental treatments for a growing number of diseases. Physicians managing patients who have received transplants abroad should be aware of the risk of infection in these patients which will be outlined in this chapter. Separate to this, the second part of this chapter addresses the topic of travel in post transplant patients. Solid organ and hematopoietic stem cell transplant recipients may wish to travel as part of their return to regular activities and lifestyle posttransplant. All transplant recipients should seek medical advice prior to travel abroad, and risk of infection will depend on destination(s) and type of travel. Risk reduction strategies are important for these patients to allow for safe travel posttransplant and will be discussed in detail in this chapter.

\section{Keywords}

Travel · Transplant Tourism · Vaccines · Solid Organ Transplant (SOT) · Hematopoeitic Stem Cell Transplant (HSCT)

\section{Introduction}

Transplant tourism and travel posttransplant both play roles in acquisition of infection in solid organ transplant (SOT) and hematopoietic stem cell transplant (HSCT) recipients. Transplant tourism refers to travel for the purpose of obtaining an organ or tissue transplant outside of a patient's usual country of residence and is often done through commercial means. Travel posttransplant refers to trips abroad taken by SOT and HSCT recipients for the purposes of business, visiting friends and relatives, or leisure. This chapter discusses both topics separately in order to best address risk of infection and strategies for prevention and treatment accordingly.

\section{Part 1: Transplant Tourism}

\section{Introduction}

The term "transplant tourism" refers to travel of either the organ donor or recipient for purposes of organ transplantation and often occurs in commercial settings [1]. Numerous international transplant organizations, including the World Health Organization (WHO), the Transplantation Society, and the International Society of Nephrology, have made efforts to decrease the purchase and sale of organs on ethical grounds [2-4], and the practice is illegal in many countries [5]. Nonetheless, these comprise an estimated $10 \%$ of SOTs worldwide [6]. Studies have found that outcomes of patients who undergo transplant through commercial means experience decreased allograft and patient survival as well as increased complications including higher rates of rejection and higher rates of infectious complications [7-13]. Although this issue is more prominent and regulations are in place to deter the practice in SOT, transplant tourism also occurs in patients seeking HSCT and stem 
cell therapies. There is growing concern for stem cell tourism, which involves stem cell therapy for a host of diseases as novel or experimental treatments beyond the traditional use for treatment of hematologic malignancies and disorders [14].

\section{Transplant Tourism and Infectious Complications}

Several publications and review papers, including guidelines published by the American Society of Transplantation Infectious Disease Community of Practice (AST Guidelines), highlight the risk of infection that comes with procuring organs through transplant tourism and commercial means $[12,15]$. The literature raises concern regarding increased risk across all categories of infection including bacterial, viral, fungal, and parasitic. Differences between endemic rates of infection, antimicrobial resistance patterns, transplant practice, and regulation are all reasons to explain this concern. Pretransplant evaluation and screening of both the donor and recipient as well as routine prophylaxis can vary by country and may not be consistent with the accepted practice, thus potentially increasing the risk of reactivation of latent infection, donor-derived infection, and perioperative or hospital-acquired infection. Furthermore, documentation of transplants that occur in foreign countries, especially for commercial purposes, may not be readily available, therefore making it difficult to provide comprehensive care once the patient returns to his/her resident country.

The body of literature addressing this issue ranges from case reports that outline individual infections acquired through foreign or commercial transplantation to single-center studies looking at outcomes of organ transplants performed in foreign countries $[7,8,16,17]$ and to review articles and guideline recommendations.

In 2013, Chen and Wilson published a review paper outlining the impact of medical tourism on the field of infectious disease. This paper highlights the magnitude of transplant tourism for both transplant and other purposes on a global scale and provides a useful overview of commonly encountered complications and their impact on healthcare. It raises issues regarding specific infections especially bacterial infections with resistant organisms that can be more common overseas. [18] Given the growing concern for multidrug-resistant organisms (MDRO) and antibiotic resistance worldwide, this is a real concern for patients who have undergone transplant abroad.

Several centers from countries including the United States, Canada, Korea, Australia, and Turkey have looked at rates of infection in patients returning from organ transplantation performed overseas compared to transplants done locally $[7,8$, $11,16,17]$. Prasad et al. have published data on outcomes in patients who underwent renal transplant commercially as compared to those done locally in Toronto, Canada $[7,8]$. The first publication reported on 20 patients who received 22 allografts obtained abroad and found increased risk of graft loss and death, and reported 11 patients had serious postoperative infections [7]. The same research group later reported on outcomes of 69 patients who received 72 commercial renal transplants which included infectious complications such as active hepatitis (4 patients), 
seroconversion of hepatitis B or C (7 patients), pulmonary tuberculosis ( 2 patients), as well as reduced allograft survival and delayed graft function [8]. Similarly, in a study by Gill et al., 33 patients who underwent transplant abroad were compared to a matched cohort done at the University of California Los Angeles (UCLA) and were found to have a more complex posttransplant course with higher incidence of severe infections [10]. Although the overall rates of infectious complications were similar $(52 \%$ vs. $48.5 \%)$, the severity of infection and the need for hospitalization were greater in those who had transplants abroad. Notably, there were more infections with cytomegalovirus (CMV) in the transplant tourism group as the majority did not receive post-transplant CMV prophylaxis when transplant was done abroad. Finally, in this study, one patient died of donor-derived hepatitis B, which highlights concern regarding screening for infection and donor selection [10].

Studies done outside of North America show similar findings in transplant tourists. An Australian review of recipients of commercial transplants done abroad found patients were at risk of transplant-related HIV infection and new hepatitis [16]. As well, a case series from Turkey reported an increased incidence of malaria, invasive fungal infection, and tuberculosis in 115 patients who had undergone commercial transplants in various countries (including India, Iraq, and Iran) as compared to patients who had undergone transplant locally from living-related donors [17].

Finally, it is important to consider that foreign-born transplant recipients may return to their country of origin for organ transplants [19, 20]. Patients will often overlook increased infection risk given they are returning home and procedures may occur either during trips for this specific purpose or while they are visiting friends and relatives. These patients are at risk for both reactivation of latent infections and acquisition of new endemic infections; knowledge of the specific infections existing in the transplant region can direct further evaluation [21].

Although less published data exists with regard to the infectious risk involved with stem cell therapy procured through medical tourism and commercial means, professional organizations including the American Society for Transplantation and Cellular Therapy have issued advisory statements on this topic [14, 22]. Concerns from an infection perspective include potential lack of pretransplant screening (both donor and recipient), differences in infection control practices, and possible exposure to multidrug-resistant pathogens and other endemic infections which can vary depending on the center [23]. Patients seeking stem cell therapies through medical tourism or commercial means should be cautioned with regard to these concerns. They should also be made aware that due to differences in healthcare regulations in various countries, stem cell therapies may be experimental or may be offered for novel diseases that have not yet been universally approved; thus, caution with regard to efficacy of treatment as well as other noninfectious complications should be taken into consideration $[14,22,24]$. 


\section{Conclusion}

Experience from transplant centers across the world has shown that there is an increased risk of infection when transplants are done through transplant tourism and in commercial settings. Therefore, identification of patients who have undergone transplant abroad and subsequent evaluation for infection upon their return to local transplant centers is important. This evaluation should include obtaining information regarding transplant process, surgical procedure, and any complications from healthcare received abroad, if possible. It is prudent to perform routine infectious disease screening as per local recommendations that may have been omitted abroad (e.g., CMV, EBV, etc.). Additional screening for endemic infections that could be donor-derived or acquired de novo while abroad based on geographic risk (malaria, strongyloides, tuberculosis, etc.), for blood-borne pathogens (HBV, HCV, and HIV), and for multidrug-resistant organisms is important to thoroughly assess. Treatment of any identified active or latent infection as well as initiation of appropriate prophylaxis as required based on routine practice and screening results will optimize care of these patients.

\section{Key Points}

- Despite regulations and laws, $10 \%$ of organ transplants occur via commercial practices.

- Patients, both SOT and HSCT, should be discouraged from this practice based on ethical reasons, but should also understand differences in outcomes and increased risk of complications.

- Transplant tourism increases risk of infection, and those patients who have received transplant abroad should be evaluated upon return to their country of residence.

- Special consideration should be paid to endemic infection based on geographic risk and should include resistant bacterial infections, mycobacterial infections, viral infections, fungal infections, and parasitic infections.

\section{Part 2: The Traveling Transplant Recipient}

\section{Introduction}

An increasing number of solid organ transplants (SOTs) and hematopoietic stem cell transplant (HSCT) are performed each year, thus expanding the population of patients who are immunocompromised posttransplant and hope to re-establish life after transplant in a safe manner. Travel is a major component of this. Studies from the United States, Canada, and Europe have shown that at least one-third of SOT patients travel outside their home country or continent [25-27]. HSCT patients also travel outside their home country; one study showed $44 \%$ of post-HSCT patients 
travel with $32 \%$ of patients traveling internationally within 2 years after HSCT [28]. As with any person wishing to travel to destinations with higher infective risk, predeparture travel medicine evaluation is recommended and is especially important in SOT and HSCT patients who are at higher risk of infection. Unfortunately, not all patients seek or receive travel advice pre-departure $[25,27,28]$. This highlights the importance of ensuring patients are aware to seek advice before planning trips especially to destinations with higher infectious risk and the role of physicians to counsel their patients to do so. The recently published AST Guidelines provide recommendations for traveling SOT recipients and emphasize the importance of addressing travel with patients prior to transplant so they are aware of the need to seek medical advice prior to future travel. [15] Similar guidelines for traveling HSCT recipients are not readily available, but the topic of travel post-HSCT is addressed as part of the American Society for Blood and Marrow Transplantation (ASBMT) Guidelines for Preventing Infectious Complications among Hematopoietic Cell Transplantation Recipients: A Global Perspective [29]. This chapter will outline specific infection that pose risk to SOT and HSCT travelers (Table 2) and ways to mitigate risk during travel, as well as provide a summary of recommendations of key components of the pre-departure travel evaluation.

\section{Risk of Infection While Abroad}

\section{Viral Infections}

\section{Respiratory Viral Infections}

\section{Influenza}

Influenza virus is a respiratory virus that is spread through respiratory droplets. Influenza causes respiratory infection that usually present with fever and cough; however, severe infections leading to respiratory failure and death occur. In fact, the WHO estimates that there are up to five million cases of severe influenza and approximately 500,000 per year globally [30]. Influenza viruses cause infections worldwide and can pose a threat to travelers, especially those with a history of transplant given higher risk of complications due to immunosuppressed state. Transplant recipients are at higher risk of severe infections, complications, and death [31, 32]. Goeijenbier et al. highlight the important considerations for the risk of acquiring influenza during travel including increased human-to-human contact while in transit or at mass gatherings, seasonality of influenza varying between hemispheres, and increased risk by geographic destination [33]. Concern exists during travel as patients transit through airports, on and off planes, trains, and other means of transportation. Proximity to potentially infected people, close spaces, and poor ventilation have all been suspected to increase transmission and attack rates. Seasonality of influenza changes by hemisphere. [34] Flu season falls between May and October in the Southern Hemisphere and between October and May in the Northern Hemisphere. In general, seasonal influenza strains in the Southern 
Hemisphere precede those seen later in the year in the Northern Hemisphere. Finally, tropical regions especially those located around the equator can have multiple influenza peaks and pose risk of transmission throughout the year. [35] Time of year and destination should be considered to ensure patients are up to date with influenza immunizations. High-risk travelers, such as transplant recipients, may warrant receiving the opposite hemisphere influenza vaccine 2 weeks prior to travel or on arrival at their travel destination [36].

\section{Measles}

Measles is a viral illness that infects the respiratory tract and leads to high fevers, upper respiratory tract symptoms, and a diffuse rash. Complications can occur, including encephalitis, and are more common in immunosuppressed patients. The virus is highly contagious and spread through respiratory secretions but can remain in the air or on surfaces for up to 2 hours [37]. Measles remains a common problem in developing countries, and despite immunization programs, there are millions of cases globally, with approximately 110,000 deaths reported in 2017. [37] More recently, measles outbreaks have become a growing global concern. The WHO reports 82,596 people in 47 of 53 countries in Europe had contracted measles in 2018. [38] Smaller outbreaks have also been recently reported across the United States and Canada. Measles vaccination is typically administrated through the combined MMR (measles, mumps, rubella) vaccine. Unfortunately, the MMR vaccine is a live vaccine and contraindicated in SOT recipients due to risk of complications including encephalitis [39-44]. Prior to travel to endemic areas or countries with ongoing outbreaks, evidence of immunity against measles should be evaluated in all SOT recipients to assess for the risk. Some transplant centers will screen and immunize prior to transplantation. For those patients who have not undergone this process pretransplant, immune status should be assessed prior to travel. Patients who were born before 1957, who have had two vaccinations, or who have had clinical disease are likely protected. Serology (measles IgG) can also be checked. [15] Immune globulin can be considered for short-term protection of nonimmune SOT recipients at high risk for exposure [43].

For HSCT recipients, live attenuated vaccines are generally considered contraindicated until 24 months posttransplant provided the patient is not suffering from graft-versus-host disease (GVHD) and is not on immunosuppressive therapy $[29,42,45-47]$. A typical practice is to perform serology (measles $\operatorname{IgG}$ ) at this time period to assess if a patient requires measles vaccination, which is generally given as the MMR vaccine. Repeat serology is often checked to ensure seroconversion and a second dose of MMR considered if patient remains seronegative. For those HSCT recipients traveling prior to this time, measles serology ( $\operatorname{IgG}$ ) could be performed early to help with risk assessment and counseling; however, reliability of this as a marker of true protection from measles early posttransplant is controversial. Therefore, risk of measles acquisition during travel should be discussed on an individual basis depending on patient, travel destination and trip itinerary factors. 


\section{Middle Eastern Respiratory Syndrome}

Middle Eastern respiratory syndrome coronavirus (MERS-CoV) belongs to the family Coronaviridae. It was first reported in 2012 and is an emerging coronavirus that causes severe acute respiratory illness [48, 49]. Cases mainly occur in the Middle East, and Saudi Arabia has reported $80 \%$ of these. Cases outside in other countries are mostly linked with travel. There have been case reports in SOT [50] and HSCT patients [51]. Transmission is poorly understood, but there is evidence to suggest person-to-person spread as well as increased risk if exposed to dromedary camels. There are no specific methods of prevention recommended for travel; however, travelers should be encouraged to take precautions including proper hand hygiene if they have been in contact with animals [48, 49]. The WHO has identified immunocompromised travels, including SOT recipients, to be at high risk of severe illness from MERS-CoV. As such, SOT recipients should avoid contact with camels and should not consume raw, undercooked, or unpasteurized camel products (i.e., meat and dairy) [48].

\section{Gastrointestinal Viral Infections}

\section{Norovirus}

Norovirus is a cause of gastroenteritis that is spread through fecal-oral routes, either person-to-person contact or from contaminated foods, mainly raw or undercooked shellfish. Norovirus has been associated as a cause of traveler's diarrhea and is more frequently seen in outbreaks linked to crowded spaces such as cruise ships $[52,53]$. While typically norovirus causes a short, self-limited gastroenteritis, transplant patients are at higher risk of complications and can go on to develop chronic norovirus [54]. Prevention involves proper hand hygiene as well as avoidance of raw or undercooked shellfish.

\section{Hepatitis A}

Hepatitis A is a frequent cause of food-borne illness and is spread through fecal-oral routes. It is associated with contaminated food and water as well as poor sanitation [55]. Clinical syndromes can range from mild illness to fulminant hepatic failure. Patients who are immunocompromised have higher risk of severe illness, and consequences can be significant.

Geographic distribution is classified as high, medium, or low risk based on endemic rates of infection. The risk of contracting hepatitis $\mathrm{A}$ in nonimmune travelers to high-risk areas is estimated at 1 in 1000 per week for those on tourist routes but increases to 1 in 200 for those on more remote itineraries [56].

Transplant recipients traveling to areas with risk of hepatitis A should be protected and should be aware of risk reduction strategies with regard to food and water precautions. [57] Unfortunately, hepatitis A vaccine is less effective in SOT recipients, and studies have shown lower rates of seroconversion [58]. Therefore, when possible, evaluation for hepatitis A serology testing should be done during transplant workup, and nonimmune patients who wish to travel posttransplant should be vaccinated prior to transplant. For HSCT recipients who plan to travel in the future, 
hepatitis A vaccine can be added to the standard posttransplant immunization schedule.

For those posttransplant patients whose immune status is unknown, hepatitis A serology should be performed. For those nonimmune transplant recipient travelers, two doses of hepatitis A vaccine 6-12 months apart should be given. If the travel departure date does not allow for both doses to be administered, the second dose should still be given upon return in order to confer longer-term protection especially for those repeat travelers. For patients who have already had one dose of vaccine previously, a second dose should be given prior to departure. Finally, for nonimmune transplant recipients who do not have adequate time prior to departure or who are unlikely to respond to immunization, pooled immunoglobulin should be given [45, 59]. Intramuscular pooled immune globulin provides $85-90 \%$ protection against hepatitis A [59]. Guidelines are available with regard to administration and dosing specifics [59].

\section{Hepatitis B}

Hepatitis B can cause illnesses ranging from an acute hepatitis to a chronic infection that can predispose to cirrhosis, liver failure, and hepatocellular carcinoma. It is transmitted through contact with infected blood or body fluids, and routes of transmission can include maternal-child, sexual contact, unsafe injections, or blood transfusions [60]. Hepatitis B, specifically chronic hepatitis B, affects over 250 million people worldwide with the highest prevalence in the Western Pacific area and Africa. [61] For SOT recipients who were not vaccinated prior to transplant, immunization against hepatitis B before travel is indicated for travelers with higher risk of exposure including those who will be living or traveling in endemic areas for extended periods; those who are likely to need medical care, procedures, or blood products while abroad; and those who anticipate having new sexual partners [15]. Again, if the patient has not been immunized prior to transplant, they can be immunized prior to departure; however, immune response to the standard hepatitis $\mathrm{B}$ vaccine posttransplant is poor. The high-dose vaccination series may be more effective in this population; therefore, immunization with a vaccine containing 40 mcg of hepatitis B surface antigen given in a three- or four-dose schedule is recommended [62]. Anti-HB titers can be measured to assess vaccine efficacy, and a titer of $>10 \mathrm{IU} / \mathrm{ml}$ is considered protective [42, 62]. Although the need for booster doses is controversial in SOT recipients, they can be considered for high-risk travelers. Hepatitis B vaccination series is typically given over a 6-month span; however, accelerating the schedule to give each vaccine dose 4 weeks apart is possible if travel departure date limits time [15].

For HSCT recipients, hepatitis B vaccine is part of the standard posttransplant immunization schedule [29, 42, 45-47]. Most schedules include a minimum of three doses of hepatitis B vaccine, and anti-HB titers can be measured to assess if booster or repeat vaccine series is required. High-dose vaccine may be more effective in this population.

The combination hepatitis A and B vaccine (such as Twinrix ${ }^{\circledR}$ ) is sometimes used for those needing both vaccines; however, the response is often poor in this patient 
population, and giving the components (A and B) separately is advised for SOT recipients.

\section{Hepatitis E}

Hepatitis $\mathrm{E}$ is another viral cause of hepatitis that is often self-limiting, but in some cases more severe infections can occur including fulminant hepatitis leading to liver failure, and cases of chronic hepatitis $\mathrm{E}$ have been seen in immunocompromised patients. [63] It is spread through fecal-oral route and associated with contaminated drinking water and poor sanitation and rarely has been transmitted through ingestion of infected animals. It is found worldwide but more common in resource-limited countries with the highest prevalence in East and South Asia. [63] There is no specific vaccine for prevention; however, patients should practice food and water precautions and avoid eating raw or undercooked meat products especially in high-risk areas [64].

\section{Polio}

Poliovirus is a neurotrophic virus that causes poliomyelitis and can lead to irreversible paralysis. It is spread through fecal-oral transmission, typically person to person, but can also be contracted through contaminated water [65]. Wild-type poliovirus has been eradicated from the Western Hemisphere; however, wild-type virus still exists in regions of sub-Saharan Africa and South Asia, and to this day, Afghanistan, Nigeria, and Pakistan remain endemic countries [66]. On occasion, outbreaks of vaccine-associated poliomyelitis have also occurred.

In efforts to eradicate polio worldwide, the majority of the population has received polio vaccine during childhood immunization series. For HSCT recipients, inactivated polio vaccine is part of the standard posttransplant schedule. Patients typically receive at least three doses and thus should be up to date once they have completed this schedule [29, 42, 45-47]. For adult SOT travelers, this should be verified, and they should also receive a booster when traveling to endemic areas. [67, 68] For subsequent travel, booster immunization may be prudent for individuals traveling to locations with circulating wild-type polioviruses or polio outbreaks.

Careful attention should be paid to the fact that two forms of the polio vaccine are available: the live oral poliovirus vaccine (OPV) and the injected inactivated poliovirus vaccine (IPV). The oral, live attenuated vaccine is contraindicated in transplant recipients. Also, household contacts of immunocompromised individuals should not receive the OPV as it is possible to spread vaccine strain poliovirus through fecal-oral contact.

\section{Vector-Borne Viral Infections}

\section{Yellow Fever}

Yellow fever (YF) virus is a flavivirus that can cause hemorrhagic fever with a $20 \%$ mortality rate. [69] It is spread through bites from mosquitos, typically the Aedes and Haemagogus species [70]. As of 2018, 47 countries in South America and Africa 
either were endemic or had areas of endemicity, with the latest outbreak occurring in Brazil [70].

The yellow fever vaccine (YFV) is an effective vaccine that offers lifelong immunity with one dose [65]. However, it contains a live attenuated viral strain and is contraindicated in SOT recipients. [41, 43, 71-73] Interestingly, a study of 53 SOT patients who received yellow fever vaccine prior to transplantation demonstrated persistence of yellow fever antibodies posttransplant; detectable antibodies persisted after a median duration of 13 years. [74] Therefore, those who plan to travel to or have reasons to potentially need to travel to yellow fever areas should be immunized pre-transplantation. Antibody testing can be done posttransplant to ensure persistent immunity, with a suggested threshold of a YF neutralization test $>10 \mathrm{U} / 1$ required for travel to high-risk areas. [74]

Those SOT recipients who have not been vaccinated or were vaccinated pretransplant but do not demonstrate protective antibodies should be advised not to travel to endemic regions. They should not receive the yellow fever vaccine posttransplant. If avoiding travel is not possible, they should not go in peak season. [43, 75]

For HSCT recipients, data is limited. As per the Guidelines: Vaccination of hematopoietic cell transplant recipients, the risk-benefit of yellow fever vaccine should be considered [45]. Since it is a live attenuated vaccine, patients should be $>24$ months posttransplant with no active GVHD and off immunosuppressive therapy [45]. A retrospective study of 21 post-allogeneic (allo)-HSCT recipients immunized with yellow fever vaccine, a median of 39 [21-86] months posttransplant, reported no side effects [76]. Thus, this vaccine could be considered for long-term survivors of HSCT who are traveling to high-risk areas, and consultation with travel medicine expert familiar with immunocompromised patient would be advised.

When yellow fever vaccine has not been given, patients should travel with a yellow fever vaccine waiver letter stating the contraindication to vaccination. Patients should be counseled to present this letter when entering countries that require proof of yellow fever vaccine and are generally acceptable to most governments.

Family members of immunosuppressed patients may receive yellow fever vaccine.

\section{Japanese Encephalitis}

Japanese encephalitis (JE) virus of the genus Flavivirus is an arbovirus that causes encephalitis. It causes up to 10,000 deaths annually in Asia and can lead to long-term neuropsychiatric sequelae in survivors [77, 78]. JE is transmitted by mosquitoes (Culex species) and is the most common vaccine-preventable encephalitis in Asia [78]. It is more common in rural and agricultural areas specifically those with significant irrigation such as rice paddies. Peak seasons occur in the summer and fall, but can vary based on rain patterns [78].

Immunization against Japanese encephalitis with two doses of inactivated JE vaccine can be considered for individuals with intense rural travel in areas of Asia 
endemic for JE, especially during periods of increased transmission [78, 79]. It is recommended for travelers with trips planned for longer than 1 month or with plans for extensive rural travel in endemic areas [80]. Although vaccine efficacy data in SOT and HSCT recipients is limited, inactivated JE vaccine is recommended in transplant recipients for the same indications. A booster dose should be given for reexposure or continued JE risk if the primary series was administered $\geq 1$ year previously. [77-79] Some JE vaccines available in Asia contain live virus; these are contraindicated in SOT recipients and those post-HSCT who do not meet LAV criteria. Patients should be aware they should not receive such vaccines [15].

\section{Dengue, Chikungunya, and Zika}

Dengue, chikungunya, and Zika are all arboviruses or arthropod-borne viruses transmitted by mosquitos, most commonly the Aedes aegypti. Although dengue is the most common mosquito-borne virus, increasing cases of chikungunya and Zika are being seen in tropical and subtropical regions [81-83]. They can all pose a risk to immunocompromised hosts including traveling transplant recipients [84]. To date, no vaccines currently exist to prevent these viral illnesses, and patients should be counseled on mosquito protection.

Dengue virus is of the genus Flavivirus. It typically causes a self-limited flu-like illness, but serious complications including dengue hemorrhagic fever and dengue shock syndrome can be fatal. Patients who have previously suffered from or been exposed to dengue fever are at increased risk of serious complications such as dengue hemorrhagic fever or dengue shock syndrome during a second infection. This is especially concerning in immunocompromised hosts [81]. Clinical course and outcomes in SOT recipients may be similar to that of immunocompetent patients, $[85,86]$ but studies have raised concern for worse outcomes including an increased risk of dengue shock syndrome leading to death as well as graft dysfunction. [87, 88] Limited data exists regarding dengue in HSCT patients, although case series of post-HSCT recipients suggests prolonged viremia in this patient population $[89,90]$.

Chikungunya is of the Alphavirus genus. It presents with some unique symptoms which helps to distinguish it from other arboviruses. Febrile illness with abrupt fevers, maculopapular rash, and arthralgias are characteristic. The disease is typically self-limited, but literature does report that SOT recipients can develop chronic polyarthritis from this viral infection [81,91].

Zika is another Flavivirus. It was first reported in Uganda, and there have been outbreaks in Africa, Asia, the Americas, and the Pacific. Most recently, in 2015, Brazil reported association between Zika, pregnancy, and microcephaly. Since then, Zika has spread throughout the Americas prompting travel recommendations for women who are or may wish to become pregnant and those interested in preventing sexual transmission of Zika [92, 93]. In adult patients, it presents as a non-specific viral illness but has been linked to Guillain-Barré syndrome (GBS). Data is limited in transplant recipients, and further studies are needed to appreciate the impact on this patient population $[81,90,94,95]$. 


\section{Rabies}

Rabies (Rhabdoviridae, genus Lyssavirus) is a neurotropic virus that causes acute encephalomyelitis. The WHO reports 59,000 deaths per year from rabies, with most cases occurring in Africa and Asia. Rabies is transmitted through the saliva from infected animal bites [96]. All mammals are susceptible to the virus, with most common being terrestrial carnivores and bats [96]. The majority of human cases occur from transmission via dog bites in endemic areas, but wild animals including bats worldwide are of concern $[96,97]$. All travelers should be counseled regarding the risk of animal bites while abroad, especially in rabies-endemic countries, and in general should avoid contact with free-roaming and wild animals. Pre-exposure rabies vaccine can be given pre-departure to select patients with high risk of exposure. For example, it may be considered in long-term travelers to endemic areas, individuals expecting significant animal exposure, and individuals who plan to be in remote areas without access to medical care $[15,96]$.

In the event of an animal bite while traveling, all transplant recipient should seek medical care. For those with rabies exposure or potential rabies exposure, patients should receive postexposure prophylaxis. This involved thorough and immediate cleansing of the wound with soap and water. Those who have not previously been immunized require human rabies immune globulin (HRIG) injected into the wound directly with the remainder given intramuscularly and postexposure prophylaxis with multidose vaccine regimen [97]. Those who have received pre-exposure prophylaxis require two more doses of the vaccine, but do not require HRIG. Since SOT recipients may not mount adequate antibody responses to the rabies vaccine, some experts recommend administration of HRIG after all at-risk exposures [80, 97, 98].

\section{Bacterial Infections}

\section{Salmonella enterica Serovar Typhi}

Salmonella enterica serovar Typhi is a bacterial infection that causes typhoid fever. It affects up to 20 million people and leads to 160,000 related deaths worldwide each year [99]. Salmonella typhi is spread through contaminated food and water and infects the gastrointestinal tract. Typhoid fever classically presents with systemic illness including high fevers, abdominal pain, and altered bowel movements. Some patients will develop blood stream infections. SOT recipients are at risk of severe complications [100].

Treatment for Salmonella typhi involves antibiotic therapy; typically, fluoroquinolones have been used, but with increasing resistance especially in South and Southeast Asia, alternatives may be needed. If possibility of resistance is high, third-generation cephalosporins are favored [101].

Given the risk of severe illness, immunization is recommended for travel to endemic areas. Two vaccines are available. The oral live attenuated vaccine is contraindicated in immunocompromised patients. Transplant recipients should receive the injectable polysaccharide vaccine. This should be given at least 2 weeks prior to departure and repeated every 2 years for ongoing travel or future trips to endemic areas. Travelers should be counseled that the immune response to 
this vaccine may be suboptimal. Travelers should be counseled about food and water precautions.

\section{Vibrio cholerae}

Vibrio cholerae is a gram-negative bacillus that infects the intestinal tract; infections in humans are most often caused by serogroups $\mathrm{O} 1$ and $\mathrm{O} 139$ which are the toxigenic strains. It is most often acquired from contaminated water but has also been associated with fish and shellfish consumption. Person-to-person transmission is possible but rare. It is generally associated with poor sanitation. Vibrio cholera is endemic in approximately 50 countries worldwide, mainly in Africa and South and Southeast Asia. It is often associated with natural disasters. For example, more recently, it has been seen more frequently in the Caribbean with a large outbreak in Haiti associated with the 2010 earthquake. Cholera presents as watery diarrhea, and when severe or if left untreated, it can cause severe fluid loss and life-threatening dehydration [102].

The mainstay of treatment is rehydration. In most countries, doxycycline is the first-line antibiotic, but patterns of resistance are emerging, and antibiotic susceptibility testing on the specimen is recommended.

Prevention of infection in travelers is mainly through food and water precautions as well as proper hand hygiene. Three inactivated oral cholera vaccines exist and include the inactivated, oral travelers' diarrhea and cholera vaccine (Dukoral $\left.{ }^{\circledR}\right)$. This vaccine offers protection against Vibrio cholera serogroup O1 [103, 104]. In general, this vaccine is not recommended routinely for travelers, but physicians may wish to consider it on an individual basis for those at high risk of exposure. [105-107] It is administered in two doses 1 week apart with a booster every 2 years if ongoing travel [103]. It is not available within the United States, but is available in other countries such as Canada. Within the United States, the oral cholera vaccine (Vaxchora ${ }^{\circledR}$ ) is a live vaccine; it is not recommended for transplant recipients as safety and efficacy have not been established in immunocompromised patients.

\section{Enterotoxigenic Escherichia coli (ETEC)}

Traveler's diarrhea is the most common travel-related illness. Bacterial pathogens are the most common cause, accounting for up to $90 \%$ of cases [108]. The enterotoxigenic strain of E. coli or ETEC is the most common cause of traveler's diarrhea. Highest-risk areas include Asia, the Middle East, Africa, Mexico, and Central and South America [109]. The route of spread is fecal-oral and mainly is acquired through contaminated food or water. Clinical presentation involves acute watery diarrhea that can become severe. The mainstay of treatment involves rehydration. Antibiotics that can be used include fluoroquinolones and macrolides; therefore, many travelers will travel with antibiotics on hand to be started based on physician instructions depending on severity and duration of traveler's diarrhea. Prevention mainly entails food and water precautions as well as proper hand hygiene. The inactivated, oral travelers' diarrhea and cholera vaccine (Dukoral ${ }^{\circledR}$ ) has not shown sufficient evidence to support reliable protection against travelers' diarrhea caused by enterotoxigenic E. coli [103, 104]. 


\section{Neisseria meningitidis}

Neisseria meningitidis is an encapsulated, gram-negative diplococcus spread person to person through aerosolized droplets or secretions. There are eight main serovars that cause invasive infections in humans. Clinical disease includes meningitis, bacteremia, and shock with high case fatality rates (5-15\%). Suspected infections require prompt evaluation, diagnosis, and treatment; typically beta-lactam antibiotics such as penicillin or ceftriaxone are recommended.

Immunization against meningococcal disease is recommended for travelers to endemic areas, such as the "meningitis belt" of sub-Saharan Africa, and for those traveling to Saudi Arabia for the Muslim pilgrimages of hajj or umra, where proof of vaccination is required [110]. SOT recipients traveling to areas of risk should receive two doses of the conjugated quadrivalent vaccine (MenACWY) prior to departure with booster repeated every 5 years. For HSCT recipients, quadrivalent meningococcal disease may be part of the standard posttransplant schedule as per country recommendations [29, 42, 45-47]. HSCT recipients who are not vaccinated and traveling to areas of risk should be immunized prior to departure. The conjugated vaccine protects against serotypes $\mathrm{A}, \mathrm{C}, \mathrm{W}$, and $\mathrm{Y}$; traditionally serotype A was of most concern for travelers, but more recently outbreaks with $\mathrm{C}$ and $\mathrm{W}$ have been seen [110]. Separate serogroup B meningococcal vaccines (MenBV) are now also available and can be considered in transplant recipients. This vaccine is not yet generally recommended for travel [110], but should be considered for transplant recipients traveling to endemic areas [80].

\section{Streptococcus pneumoniae}

Streptococcus pneumoniae is a gram-positive coccus, and infection with this bacterium causes clinical presentations such as pneumonia, bacteremia, and meningitis. It is one of the most common causes of community-acquired pneumonia worldwide. Developing countries have higher incidence [111]. Treatment of infection involves antibiotic therapy with beta-lactam or macrolide; the antibiotic choice, route, and duration depend on diagnosis and severity of the illness. For prevention, two pneumococcal vaccines are available, and transplant recipients should be up to date prior to travel if these have not been administered within the past 5 years. SOT recipients should have received at least one dose of the conjugated pneumococcal vaccine (Prevnar ${ }^{\circledR} 13$, PCV13) followed by the polysaccharide pneumococcal vaccine (Pneumovax ${ }^{\circledR} 23$, PPSV23) [42, 44]. HSCT recipients should complete pneumococcal vaccines as part of the standard posttransplant schedule, receiving multiple doses of the conjugated vaccine and finishing with the polysaccharide [29, $42,45-47]$.

\section{Clostridium tetani}

Clostridium tetani is an anaerobic gram-positive bacillus that causes tetanus. It is distributed worldwide in the environment, but is more common in rural areas [112]. It is transmitted through contact with broken skin barrier, often occurring during an injury. Tetanus causes acute spasms and muscle rigidity, often starting locally but can become generalized and lead to death. Treatment involves wound care, tetanus immune globulin, antibiotic therapy typically with metronidazole, tetanus toxoid 
vaccine, and supportive management. Infection can be prevented through immunization, which is universally recommended. Although tetanus is rare among travelers, all transplant recipients should have a tetanus booster if they are not up to date before traveling. Patients can be immunized with combination vaccine for tetanus, diphtheria, and acellular pertussis (Tdap) [42].

\section{Corynebacterium diphtheriae}

Corynebacterium diphtheriae causes diphtheria; most commonly respiratory diphtheria can cause inflammation of pseudomembranes which can lead to fatal airway obstruction. Mortality occurs in 5-10\% of cases. It is transmitted person to person through droplets. In tropical countries, cutaneous diphtheria can occur through direct skin contact. Diphtheria continues to be endemic in many countries worldwide with outbreaks occurring. It is more common in resource-poor regions. Treatment requires diphtheria antitoxin and antibiotic therapy, usually penicillin or macrolides. Diphtheria toxoid vaccine is universally recommended, and travelers, including transplant recipients, should be up to date. A booster should be administered prior to travel to endemic areas or those with outbreaks if patients were last vaccinated more than 10 years previously. Patients can be immunized with combination vaccine for tetanus, diphtheria, and acellular pertussis (Tdap) [42].

\section{Bordetella pertussis}

Bordetella pertussis is a gram-negative aerobic bacillus that causes pertussis or more casually known as whooping cough. It is highly communicable with transmission via respiratory droplets. Unfortunately, worldwide incidence of pertussis is on the rise, with $90 \%$ of pertussis occurring in developing countries. Treatment is with antibiotic therapy with macrolides, specifically erythromycin, recommended first line. [113] All travelers including transplant recipients should be protected [114]. Patients can be immunized with combination vaccine for tetanus, diphtheria, and acellular pertussis (Tdap) [42].

\section{Mycobacterial Infections}

\section{Mycobacterium tuberculosis}

Mycobacterium tuberculosis is an acid-fast bacillus that causes tuberculosis (TB). It is transmitted person to person through airborne particles. TB can lead to both active, pulmonary and extrapulmonary, and latent infections. In 2017, the WHO reported an estimated ten million new cases of TB and 1.6 million deaths [115]. Immunocompromised patients, including transplant recipients, are at higher risk of TB. In these patients, most cases are felt to be reactivation of latent infection from prior exposure; however, new infection can be acquired posttransplant with higher risk in endemic countries. Clinical manifestation of TB in SOT recipients can present differently, and mortality rates are high [116]. Treatment of active TB involves multidrug regimen with careful consideration for interactions with immunosuppressive therapy. 
Although there are no specific recommendations for prevention of TB exposure in travelers, transplant recipients should be cognizant of risk while traveling in endemic areas for prolonged periods of time or if their itinerary involves high-risk exposure. For example, use of an appropriate mask (fitted N95) for those working or volunteering in high-risk healthcare settings in endemic regions should be considered [15]. If there is concern for TB exposure while abroad, a post-travel tuberculosis skin tests with the purified protein derivative (PPD) or an interferongamma release assay may be helpful; however it should be noted that immunocompromised patients are at risk of false-negative tests. TB screening in asymptomatic patients should only be done if there is a known exposure to active tuberculosis infection or if there has been prolonged exposure in a high-risk environment such as working or volunteering in a healthcare setting in an endemic area [117]. The bacillus Calmette-Guérin (BCG) vaccine is a live attenuated strain of M. bovis and is contraindicated in transplant recipients due to risk of disseminated BCG infection.

\section{Fungal Infections}

SOT and HSCT recipients are at higher risk for fungal infection compared to the immunocompetent population. Although this risk is universal and not limited to travel exposures, certain fungal infections are known to be linked to geographic areas. $[118,119]$ Transmission or acquisition of infection is generally through environmental exposures and most commonly through inhalation or cutaneous inoculation. Clinical presentation is variable and depends on organ system involved, but can include pulmonary disease, cutaneous disease, rhino-orbital-cerebral disease, and disseminated infection among others. Optimal antifungal therapy depends on the fungal species responsible for infection, and surgical excision or debridement should be considered when appropriate or necessary for source control. Prevention revolves around avoidance of high-risk environmental exposures.

Certain geographic areas pose higher risk of endemic fungal infections. In 2002, Ericsson et al. published a review of fungal infections among returning travelers that had been reported through the GeoSentinel network [120]. This study reported up to $0.5 \%$ monthly morbidity of illness in returning travelers was due to fungal infection and specifically review cases due to histoplasmosis, coccidioidomycosis, and penicilliosis (now talaromycosis). In 2013, Lortholary et al. reviewed the published literature of fungal infections in immunocompromised travelers [121]. Endemic fungal infections, including histoplasmosis, blastomycosis, and coccidioidomycosis in North America, paracoccidioidomycosis in South America, and talaromycosis due to Talaromyces (formerly Penicillium) marneffei infection in Southeast Asia, can be acquired during travel $[21,80,119-124]$. More details on the geographic distribution of these endemic fungal infections are summarized in Table 1.

Transplant recipients should be counseled to be diligent with regard to avoiding high-risk exposures for respiratory exposures such as visiting caves (spelunking). If exposures cannot be avoided, surgical masks can be worn to reduce risk of inhalational exposure. Other fungal infections can be transmitted through direct skin inoculation from the environment; thus gloves or skin covering can be donned to minimize direct skin inoculation. 
Table 1 Geographic distribution of endemic fungal infections

\begin{tabular}{|c|c|}
\hline Fungal infection & Geographic distribution \\
\hline \multicolumn{2}{|l|}{ Blastomycosis } \\
\hline $\begin{array}{l}\text { Blastomyces } \\
\text { dermatitidis }\end{array}$ & $\begin{array}{l}\text { Midwestern, South Central, and Southeastern United States and Canada } \\
\text { (especially Ohio and Mississippi Rivers, the Great Lakes, Saint } \\
\text { Lawrence River, and Northern Ontario) }\end{array}$ \\
\hline \multicolumn{2}{|l|}{ Coccidioidomycosis } \\
\hline $\begin{array}{l}\text { Coccidioides immitis } \\
\text { Coccidioides } \\
\text { posadasii }\end{array}$ & $\begin{array}{l}\text { Southwestern United States (Arizona, California, Nevada, New Mexico, } \\
\text { Texas, Utah), Mexico, and Central and South America }\end{array}$ \\
\hline \multicolumn{2}{|l|}{ Cryptococcosis } \\
\hline Cryptococcus gattii & $\begin{array}{l}\text { Pacific Northwest United States (Washington, Oregon) and Canada } \\
\text { (British Columbia and Vancouver Island), Australia, Papua New Guinea } \\
\text { Also seen in parts of Africa, Asia, Europe, Mexico, and South America }\end{array}$ \\
\hline \multicolumn{2}{|l|}{ Histoplasmosis } \\
\hline $\begin{array}{l}\text { Histoplasma } \\
\text { capsulatum }\end{array}$ & $\begin{array}{l}\text { Worldwide especially river valleys in the United States (Ohio and } \\
\text { Mississippi Rivers), Canada (Ontario, Quebec especially Saint } \\
\text { Lawrence River) } \\
\text { Also seen in Central and South America, Africa, Asia, and Australia }\end{array}$ \\
\hline \multicolumn{2}{|l|}{ Paracoccidioides } \\
\hline $\begin{array}{l}\text { Paracoccidioides } \\
\text { brasiliensis }\end{array}$ & $\begin{array}{l}\text { Central and South America (Brazil, Venezuela, Colombia, and } \\
\text { Argentina) }\end{array}$ \\
\hline \multicolumn{2}{|l|}{ Talaromycosis } \\
\hline $\begin{array}{l}\text { Talaromyces } \\
\text { marneffei }\end{array}$ & Southeast Asia, southern China, eastern India \\
\hline
\end{tabular}

\section{Parasitic Infections}

A wide variety of parasites exist worldwide and are generally classified as helminths, protozoa, and ectoparasites. They can cause infection of the blood, tissue, and intestinal tract in human hosts. In SOT recipients, parasite infections can occur through reactivation, donor-derived acquisition, or de novo acquisition, especially in patients who live or spend prolonged periods of time in endemic areas. A Canadian study found $29 \%$ of 3,528 returning travelers, and new immigrants had parasitic infection [125]. Travelers who were visiting friends and relatives (VFR) seemed to be at high risk. With increasing travel among SOT recipients, the incidence of parasitic infections in returning travelers is expected to grow [126] (Tables 3 and 4).

\section{Vector-Borne Parasite Infections}

Vectors, mainly insects, can spread parasite infections to human hosts. These include through mosquitos (Plasmodium spp.), sand flies (Leishmania spp.), triatomine bugs or tsetse flies (Trypanosoma spp.), and ticks (Babesia spp.) [127].

\section{Plasmodium Species}

Five species of Plasmodium, including P. falciparum, P. vivax, P. ovale, P. malariae, and $P$. knowlesi, cause malaria. Malaria remains a large global health problem with 
Table 2 Travel-related infections by organism

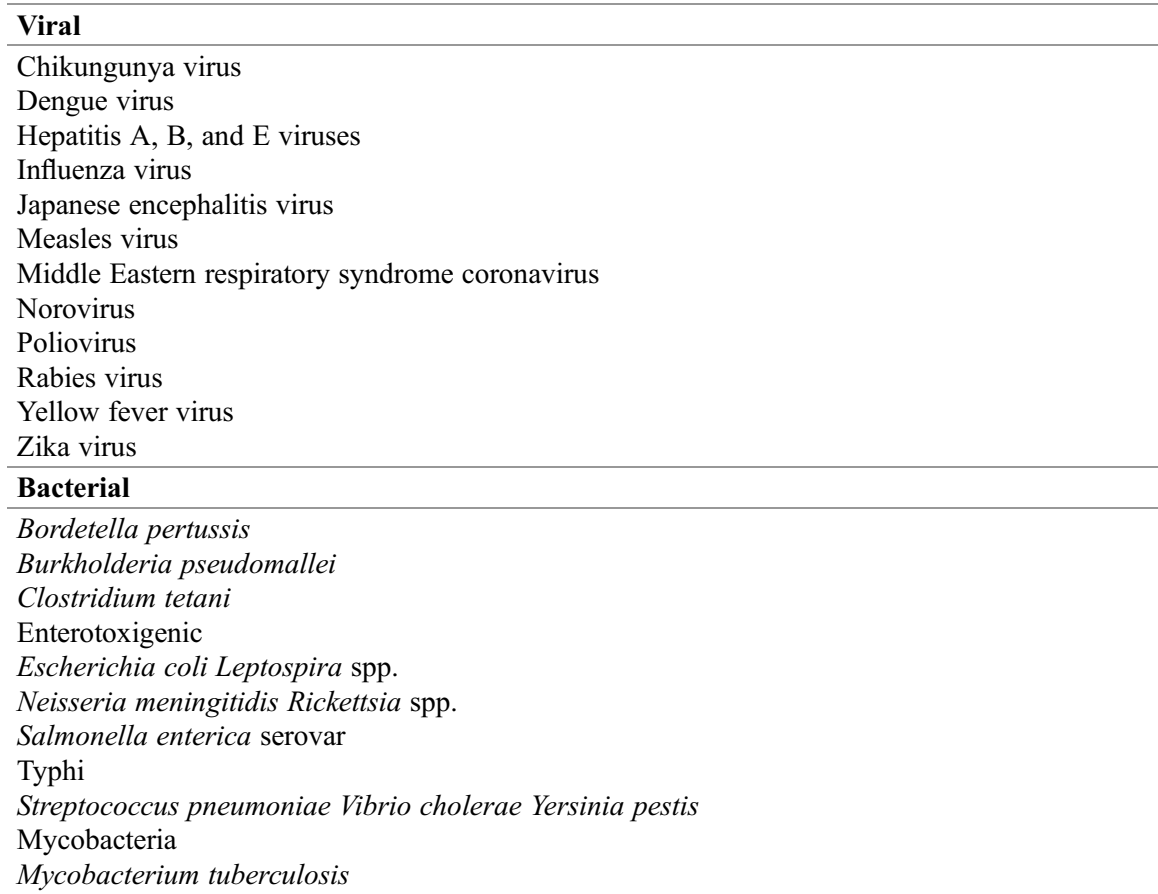

Fungal

Blastomyces dermatitidis

Coccidioides immitis

Coccidioides posadasii

Cryptococcus gattii

Histoplasma capsulatum

Paracoccidioides brasiliensis

Talaromyces marneffei

Parasites

Cryptosporidium spp.

Cyclospora cayetanensis

Babesia spp.

Brugia spp.

Entamoeba spp.

Fasciola spp.

Giardia intestinalis

Leishmania spp.

Onchocerca volvulus

Schistosoma spp.

Strongyloides stercoralis

Taenia spp.

Toxoplasma gondii

Wuchereria bancrofti 
most recent estimates of 219 million infections in 87 countries and 435,000 deaths worldwide [128]. It is transmitted through mosquitos (female Anopheles). Malaria is an acute febrile illness that can quickly progress to severe illness and death if left untreated. Like all travelers to endemic areas, transplant recipients are at risk. Treatment involves prompt diagnosis and administration of antimalarials; the choice and route depend on causative species, area of acquisition along with known resistance patterns, level of parasitemia, and severity of illness. Supportive care and close monitoring are especially important in severe disease.

Patients traveling to malaria areas should be provided prophylaxis prior to departure and be counseled on insect protection including use of bed nets. Transplant recipients should be provided prophylaxis against malaria as per routine recommendations based on area of travel and resistance patterns, but careful attention needs to be paid to drug interactions with immunosuppressive therapy [129]. The Center for Disease Control (CDC) Yellow Book among other resources provides countryspecific guidelines and patient-related considerations for selecting a prophylactic agent [130]. The AST Guidelines provide additional information including a summary of antimalarial interactions with common medications taken by SOT recipients including calcineurin inhibitors, mTOR inhibitors, and/or trimethoprimsulfamethoxazole [15], some of which are also by HSCT recipients. This information has been adapted from several references and summarized in Table 5.

\section{Leishmania Species}

Leishmania species cause protozoan infection known as leishmaniasis that can be classified as cutaneous, mucocutaneous, or visceral. An estimated one million new cases occur globally each year [131]. Visceral leishmaniasis most often occurs in Brazil, Southeast Asia, and East Africa, whereas cutaneous leishmaniasis is more common in the Mediterranean Basin, Middle East, and Central Asia [131]. Transmission is through sandfly bites. Immunocompromised patients, including SOT recipients, are at higher risk of developing disease and more severe infection [132]. Treatment requires prompt diagnosis and treatment, with options including amphotericin B, pentavalent antimonials, miltefosine, and paromymycin [132]. Although rare, travelers can be exposed when visiting endemic regions. Transplant recipients should take precautions to prevent sandfly bites including use of protective clothing, insect repellent, and treated bed nets and minimize activities during dusk hours $[82,133]$.

\section{Trypanosoma Species}

Trypanosoma species are protozoan parasites that cause two specific disease entities.

In Africa, Trypanosoma brucei is transmitted through the tsetse fly and causes African trypanosomiasis or sleeping sickness. Fortunately, due to control efforts, the WHO reports a significant drop in the number of cases and is targeting elimination by 2020 [134]. Therefore, this is unlikely to pose a significant risk to travelers; however, transplant recipients should still take precautions to avoid tsetse fly bites while traveling to endemic areas. 
Of more significant concern, in the Americas, Trypanosoma cruzi is transmitted through feces of triatomine insects and causes American trypanosomiasis or Chagas disease. It can also be transmitted through blood transfusions and organ transplantation. It is endemic in Mexico and Central and South America. The WHO reports an estimated seven million people worldwide are infected [135]. The disease can cause an acute phase and chronic phase, with the chronic phase leading to cardiomyopathy and disease involving the gastrointestinal tract and nervous system [135, 136]. Treatment requires trypanocidal therapy with benznidazole [136]. The risk of acquiring de novo infection can occur while traveling; however, the incidence of this occurrence is thought to be quite low. Nonetheless, transplant recipients should take precautions to minimize exposure to triatomine bugs by avoiding sleeping in thatched, mud, or adobe housing, by avoiding consumption of products that may have been contaminated with insect feces, and by being cautious of blood transfusions in endemic areas [136, 137].

\section{Babesia Species}

Babesia species are protozoan parasites which are transmitted through bites by Ixodes ticks. Cases have been reported worldwide; however, they are seen mostly in North America and Europe. Areas of high risk within North America include the Northeast and Midwest United States. Clinical infection can range from asymptomatic to flu-like illness to hemolytic anemia and thrombocytopenia. SOT recipients are at higher risk of severe and fatal infection even with proper treatment [138]. Other immunocompromised patients, including HSCT recipients and especially patients with asplenia, can also have more severe disease and are at risk for prolonged or refractory infection [139, 140]. Treatment consists of combination therapy with atovaquone plus azithromycin or clindamycin plus quinine; duration of therapy may need to be extended in transplant recipients. In some patients, exchange transfusion may be indicated. Transplant recipients traveling to endemic areas, especially those with plans for significant outdoor activities, should take steps to prevent tick exposure including wearing long sleeves and using insect repellent (DEET). Tick checks should be performed on a regular basis [127].

\section{Environmentally Transmitted Parasite Infections}

Parasites can be transmitted through penetration of the skin during environmental exposures such as direct contact with soil or water. These parasites include hookworm (Ancylostoma duodenale and Necator americanus), Strongyloides stercoralis, and Schistosoma species.

\section{Strongyloides stercoralis}

Strongyloides stercoralis is a helminth or worm. Upwards of 100 million people worldwide are infected. It is found mainly in tropical and subtropical regions but has been reported in temperate climates as well. It is acquired by direct contact with contaminated soil. It can lead to asymptomatic infection or can cause strongyloidiasis affecting the intestinal tract, lungs, and skin. Patients with immunocompromising conditions, including SOT and HSCT recipients, are at higher risk of 
severe disease including hyperinfection syndrome and disseminated strongyloidiasis. This can lead to critical illness including shock and multi-organ failure with high rates of mortality. Treatment is with ivermectin, and duration depends on the type and severity of infection. Albendazole is an alternative. The risk for short-term travel is low but can increase with prolonged time spent in endemic areas or participating in activities that would increase exposure. Transplant recipients should wear appropriate footwear/shoes while in endemic areas especially if walking in areas that could be contaminated with human feces [141, 142].

\section{Schistosoma Species}

Schistosoma spp. are helminths that cause schistosomiasis. Species vary between geographic regions, and clinical syndrome can depend on which species is involved. The majority of the cases occur in Africa, and most common species include $S$. mansoni and $S$. haematobium. Other affected areas include the Middle East $(S$. haematobium) and Asia (S. japonicum, S. mekongi). Travelers often acquire infection in sub-Saharan Africa. Exposure is through freshwater in endemic areas with infection acquired when swimming, bathing, or wading in contaminated water. Clinical presentation of acute infection, known as Katayama syndrome, consists of fever, headache, diarrhea, and respiratory symptoms. Chronic disease can develop and depends on the type of species causing the infection with $S$. mansoni and $S$. japonicum, whereas $S$. haematobium affects the urinary tract. Treatment is with praziquantel. Travelers to endemic areas should avoid freshwater exposures including swimming, bathing, wading, water adventure sports, etc. [142, 143]

\section{Ingested Parasitic Infections}

Parasite infections can be acquired through ingestion of contaminated food or water or accidental ingestion of contaminated dirt/soil. These parasites include amebiasis (Entamoeba spp.), cryptosporidiosis (Cryptosporidium spp.), cyclosporiasis (Cyclospora cayetanensis), fascioliasis (Fasciola spp.), giardiasis (Giardia intestinalis), taeniasis (Taenia spp.), and toxoplasmosis (Toxoplasma gondii) among others. Geographic distribution, syndromes, and treatments are infection specific, and more information can be found in Chapter 3 of the CDC Yellow Book [144] and in the AST Guidelines on Parasitic Infections in Solid Organ Transplantation [126]. Generally speaking, for all of these parasitic infections, prevention centers around precautions to prevent food- and water-borne illnesses. Transplant recipients traveling to endemic areas or areas with poor sanitation should avoid eating raw or undercooked meats and fish and raw fruits and vegetables that they cannot peel themselves and should ensure safe drinking water. They should not drink from freshwater sources such as lakes, rivers, and streams.

\section{Pre-departure Infectious Disease Evaluation and Recommendations}

SOT and HSCT recipients who plan to travel should seek advice from a travel medicine specialist. All transplant recipients should be counseled on the importance 
of safe travel posttransplant and value of pre-departure assessment; this should be included as part of their pretransplant education and teaching.

SOT recipients should be advised not to travel to high-risk areas during times of increased immunosuppression such as the first year posttransplant or after treatment for rejection. [43, 80, 145] Recommendations for timing of travel post-HSCT depend on the type of transplant. Allo-HSCT recipients should be advised not to travel to high-risk areas for the first 6-12 months posttransplant or if on treatment for graft-versus-host disease (GVHD) with immunosuppressive therapy, whereas autologous (auto)-HSCT recipients may be able to travel as soon as 3-6 months posttransplant [146]. All patients should consult with their transplant physician(s) to ensure it is safe to travel as decisions should be made on an individual basis. Although patients may be out of the highest-risk period, it is important to note the post-HSCT immunization schedule is generally not completed until 24 months posttransplant date. Thus, this should be taken into consideration when determining timing of travel posttransplant and when providing recommendations for minimizing the risk of infection while traveling.

Infectious risk depends on the travel itinerary by both destination and type of travel, and recommendations for prevention of infection will vary accordingly. Important elements of the pre-departure evaluation include review of past medical history, current medications, and travel itinerary including destinations, accommodation type, and potential exposures; counseling on risk reduction strategies; counseling on when and where to seek medical attention should they fall ill while away; administration of recommended vaccinations; and prescribing of prophylactic medications. Patients should verify travel insurance coverage prior to departure. Finally, a review of important items in the form of a packing list may also be helpful for travelers. Examples of such lists can be found in the CDC Yellow Book and the AST Guidelines [15, 147].

\section{Vaccine Recommendations}

Patients should be advised to seek pre-travel advice early when planning trips as full vaccine series may require several months prior to departure. Passive immunization with immune globulin can be considered for urgent travel situations. When possible, if patients indicate plans to travel after SOT, travel-related vaccines can be considered pretransplant. This is especially important if there is a need for live attenuated vaccines which are contraindicated posttransplant. SOT recipients should be up to date with their routine immunizations as immunocompromised individuals are at risk of common infections both at home and abroad. Recommendations are available through the AST Guidelines, the CDC, and other publications on routine immunizations in SOT recipients. [44, 114, 148, 149] More specific information regarding travel-related vaccines in immunocompromised individuals can be found in the Yellow Book [43] and other publications including recommendations for SOT recipients who travel specifically $[15,72,80,148,150,151]$. Recommended immunizations have been summarized based on these recommendations in Table 3. Patients should travel with their immunization records as well as a waiver for yellow fever immunization indicating contraindication. 
Table 3 Recommendations for vaccination for solid organ transplant travelers [15], 44, 72]

\begin{tabular}{|c|c|}
\hline Vaccine & Recommendations for adults \\
\hline \multicolumn{2}{|l|}{ Routine immunizations } \\
\hline Parenteral influenza & $\begin{array}{l}\text { Yearly } \\
\text { Should be considered prior to travel for patients traveling to } \\
\text { opposite hemisphere during flu season }\end{array}$ \\
\hline $\begin{array}{l}\text { Pneumococcal conjugated and } \\
\text { polysaccharide }\end{array}$ & Recommended; booster after 5 years \\
\hline Tetanus/diphtheria & Recommended; booster every 10 years \\
\hline Pertussis & $\begin{array}{l}\text { Recommended in combination with tetanus and diphtheria } \\
\text { (Tdap) once }\end{array}$ \\
\hline $\begin{array}{l}\text { Measles, mumps, and rubella } \\
(\mathrm{MMR})^{\mathrm{a}}\end{array}$ & $\begin{array}{l}\text { Contraindicated } \\
\text { If serostatus or immunization history is unknown, perform } \\
\text { serology prior to travel to areas of outbreak }\end{array}$ \\
\hline Varicella $^{\mathrm{a}}$ & Contraindicated \\
\hline \multicolumn{2}{|l|}{ Travel immunizations } \\
\hline Hepatitis A & Recommended when indicated \\
\hline Hepatitis B & Recommended when indicated \\
\hline Meningococcal conjugate & Recommended when indicated \\
\hline Meningococcal serogroup B & Recommended when indicated \\
\hline $\begin{array}{l}\text { Inactivated polio vaccine } \\
\text { (IPV) }\end{array}$ & Recommended when indicated \\
\hline Rabies & Recommended when indicated \\
\hline $\begin{array}{l}\text { Japanese encephalitis } \\
\text { (inactivated) }\end{array}$ & Recommended when indicated \\
\hline Cholera vaccine & $\begin{array}{l}\text { Recommended when indicated; non-live available in Canada } \\
\text { and elsewhere; live vaccine contraindicated }\end{array}$ \\
\hline Typhim Vi & Recommended when indicated \\
\hline S. typhi Ty21a & Contraindicated \\
\hline Oral polio vaccine $(\mathrm{OPV})^{\mathrm{a}}$ & Contraindicated in patients and family/household members \\
\hline $\begin{array}{l}\text { Bacillus Calmette-Guérin } \\
(\mathrm{BCG})^{\mathrm{a}}\end{array}$ & Contraindicated \\
\hline Yellow fever vaccine $(Y F V)^{\mathrm{a}}$ & Contraindicated \\
\hline
\end{tabular}

Adapted from the Centers for Disease Control and Prevention "Recommended Adult Immunization Schedule - United States, 2018,“ [114] "Advising Travelers with Specific Needs: The Immunocompromised Traveler" [43] in Centers for Disease Control and Prevention's "Health Information for International Travel," "Guidelines for vaccination of solid organ transplant candidates and recipients" [44], and the AST Guidelines [15]

${ }^{a}$ Live attenuated

Recommended immunizations for HSCT recipients differ from those recommended for SOT. Typically, HSCT patients receive extensive immunization schedule posttransplant as it is believed their previous immunity to vaccine-preventable diseases (VPDs) may have been eliminated during the transplant process. Although post-HSCT immunization schedules differ between allo- and auto-HSCT recipients, both take approximately 18 months to complete and typically finish around 24 months posttransplant [42, 45, 47, 146, 152]. The last immunizations in 
these series are the live attenuated vaccines, including measles, mumps, and rubella (MMR) and varicella. For those patients who plan to travel once deemed safe to do so, common travel-related vaccines, such as hepatitis A, can be built into the standard immunization schedule. Specific travel-related vaccines should be considered on an individual basis and take into consideration the destination and trip itinerary [29, 47]. Recommended immunizations have been summarized in Table 4.

\section{Risk Reduction of Non-vaccine-Preventable Infections}

Education and counseling of patients prior to departure plays an important role in minimizing risk during travel. The AST Guidelines provide further information and helpful summary tables on important travel-related topics for SOT [15]. Similarly, the ASBMT Guidelines provide information for HSCT patients [29]. Basic infectious precautions including hand hygiene, avoiding sick contacts, and use of procedure mask while in transit (e.g., airplanes) or participating in high-risk activities should be reviewed.

\section{Prevention of Food-Borne Illnesses and Diarrhea}

Diarrhea is the most common illness of travelers, especially in travelers to lowresource countries. Although, in general, many episodes can be mild and self-limited, travelers' diarrhea can lead to complications and can even be lifethreatening. Transplant recipients should be instructed on appropriate food and water precautions [105, 153-155]. They should avoid beverages that contain local water or ice and only drink boiled or bottled water. Other high-risk food and drink including unpasteurized dairy products, raw meats and fish, and undercooked foods should be avoided. Consumption of fruits and vegetables should be restricted to those they can peel themselves. All travelers should carry appropriate antibiotics for self-treatment of traveler's diarrhea. The choice of antibiotic depends on local resistance patterns of enteric pathogens, $[105,106,156]$ and interactions with immunosuppressive agents should be taken into consideration (Table 5). Patients should be counseled on when to seek medical attention, such as non-resolving diarrhea, fever, or bloody stools.

\section{Respiratory Infections}

Respiratory infections are the second most common infection affecting travelers [56]. High-risk periods of travel include while in transit through public spaces such as airports or while on airplanes. Masks may be helpful in preventing respiratory infections. Active outbreaks of respiratory infections may warrant deferring travel.

\section{Insect Protection}

Travelers to areas endemic for mosquito- and tick-borne diseases should be counseled about minimizing insect bites. Strategies including use of repellents containing DEET (N,N-diethyl-3-methylbenzamide), protective clothing with long sleeves, and permethrin-impregnated clothing and bed nets should be considered $[43,105]$. Efforts should be made to choose accommodation with air conditioning and screens. 
Table 4 Recommendations for vaccination for hematopoietic stem cell transplant travelers

\begin{tabular}{|c|c|}
\hline Vaccine & Recommendations for adults \\
\hline \multicolumn{2}{|l|}{ Routine immunizations } \\
\hline Parenteral influenza & $\begin{array}{l}\text { Yearly } \\
\text { Should be considered prior to travel for patients traveling to } \\
\text { opposite hemisphere during flu season }\end{array}$ \\
\hline $\begin{array}{l}\text { Pneumococcal conjugated } \\
\text { and polysaccharide }\end{array}$ & $\begin{array}{l}\text { Recommended as part of post-transplant immunization series; } \\
\text { booster after } 5 \text { years }\end{array}$ \\
\hline Tetanus/diphtheria & $\begin{array}{l}\text { Recommended as part of post-transplant immunization series; } \\
\text { booster every } 10 \text { years }\end{array}$ \\
\hline Pertussis & Recommended as part of post-transplant immunization series \\
\hline Hepatitis B & Recommended as part of post-transplant immunization series \\
\hline $\begin{array}{l}\text { Inactivated polio vaccine } \\
\text { (IPV) }\end{array}$ & Recommended as part of post-transplant immunization series \\
\hline Meningococcal conjugate & Recommended as part of post-transplant immunization series \\
\hline $\begin{array}{l}\text { Measles, mumps, and rubella } \\
(\mathrm{MMR})^{\mathrm{a}}\end{array}$ & $\begin{array}{l}\text { Typically given if serology indicates nonimmune at } 24 \text { months } \\
\text { post-transplant if patient meets criteria to receive live attenuated } \\
\text { vaccine (LAV) }\end{array}$ \\
\hline Varicella $^{\mathrm{a}}$ & $\begin{array}{l}\text { Typically given if serology indicates nonimmune at } 24 \text { months } \\
\text { post-transplant if patient meets criteria to receive live attenuated } \\
\text { vaccine (LAV) }\end{array}$ \\
\hline \multicolumn{2}{|l|}{ Travel immunizations } \\
\hline Hepatitis A & Recommended when indicated \\
\hline Meningococcal serogroup B & Recommended when indicated \\
\hline Rabies & Recommended when indicated \\
\hline $\begin{array}{l}\text { Japanese encephalitis } \\
\text { (inactivated) }\end{array}$ & Recommended when indicated \\
\hline Cholera vaccine & $\begin{array}{l}\text { Recommended when indicated; non-live available in Canada } \\
\text { and elsewhere; live vaccine contraindicated }\end{array}$ \\
\hline Typhim Vi & Recommended when indicated \\
\hline S. typhi Ty21a & $\begin{array}{l}\text { Contraindicated; an inactivated vaccine exists and is } \\
\text { recommended for these patients }\end{array}$ \\
\hline Oral polio vaccine $(\mathrm{OPV})^{\mathrm{a}}$ & $\begin{array}{l}\text { Contraindicated; an inactivated vaccine exists and is } \\
\text { recommended for these patients }\end{array}$ \\
\hline $\begin{array}{l}\text { Bacillus Calmette-Guérin } \\
(\mathrm{BCG})^{\mathrm{a}}\end{array}$ & Contraindicated \\
\hline Yellow fever vaccine $(Y F V)^{a}$ & $\begin{array}{l}\text { Contraindicated, however, may be considered if indicated if } \\
\text { patient is } 24 \text { months post-transplant and meets criteria to receive } \\
\text { live attenuated vaccine (LAV) }\end{array}$ \\
\hline
\end{tabular}

Adapted from the Centers for Disease Control and Prevention "Recommended Adult Immunization Schedule - United States, 2018," [114] "Advising Travelers with Specific Needs: The Immunocompromised Traveler" [43] in Centers for Disease Control and Prevention's "Health Information for International Travel," and ASBMT: Guidelines for Preventing Infectious Complications among Hematopoietic Cell Transplantation Recipients: A Global Perspective [29]

${ }^{a}$ Live attenuated

${ }^{b}$ Criteria to receive $L A V: \geq 24$ months post-HSCT, no active GVHD, no immunosuppressive therapy 


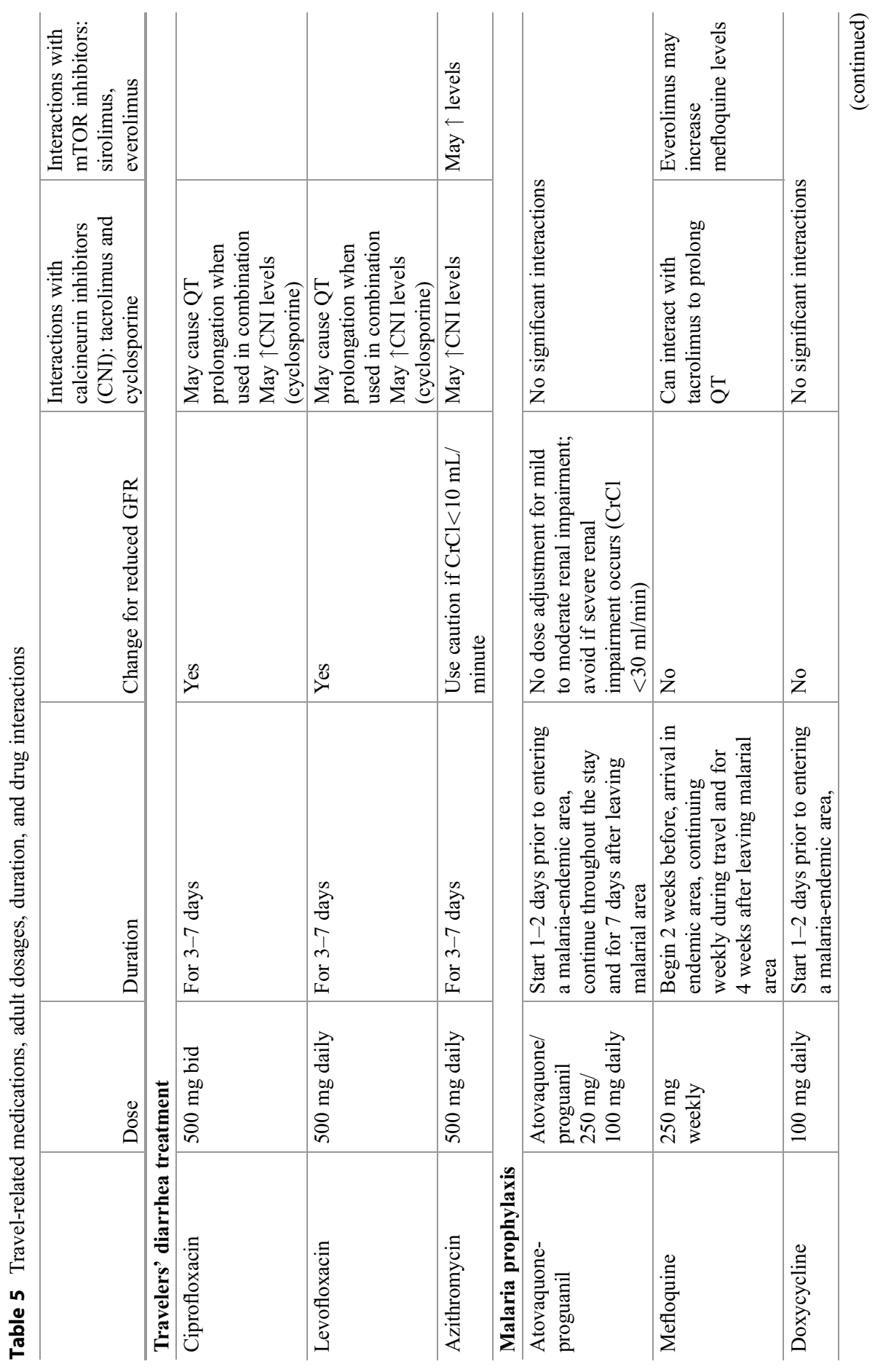




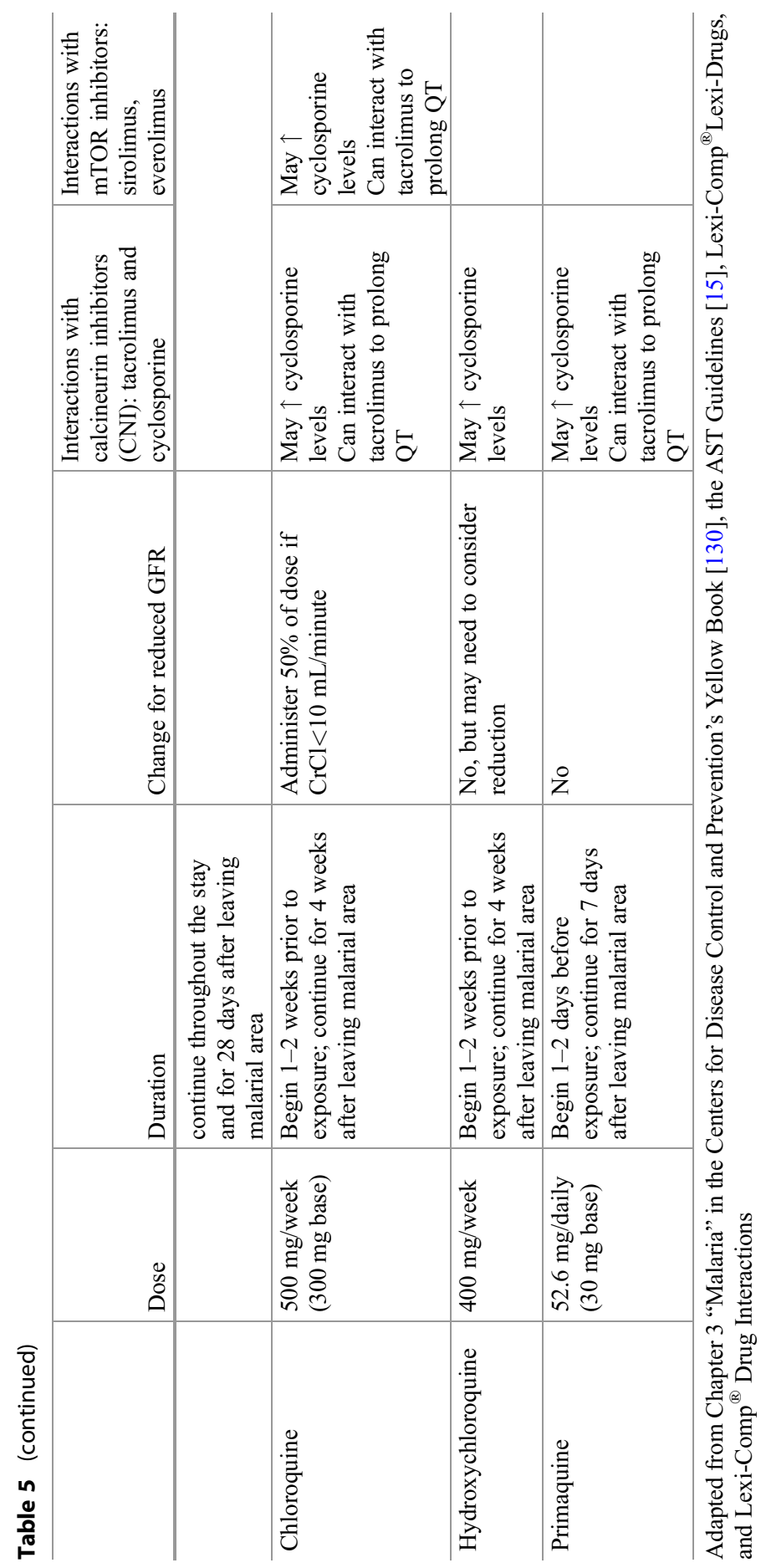




\section{Environmental Exposures}

Infections that exist in the environment can pose a threat and include those that transmit via direct contact and those that transmit via respiratory particles or spores.

Water and soil exposure can pose a risk of infections through direct contact. Travelers should avoid swimming or bathing in freshwater when traveling in areas endemic for Schistosoma and should always wear footwear when in regions endemic for Strongyloides stercoralis [82].

Exposure to endemic fungal infections occurs through inhalation of spores found in the environment. Transplant recipients should avoid activities that place them at higher risk of exposure, and use of procedural masks may help prevent acquisition of infection.

\section{Blood-Borne Pathogens}

Travelers should avoid contact with non-sterile needles, syringes, and other medical equipment. If travel is planned to regions where healthcare settings may not be reliable, travelers should consider a first aid kit equipped with sterile needles, syringes, and sutures in case required while abroad.

\section{Sexually Transmitted Infections (STI)}

Travelers may be more likely to engage in sexual activity with new partners, counseling should be provided with regard to safe sex practices, and patients should be encouraged to have STI screening performed upon return home should they engage with new partners while abroad.

\section{Post-travel Evaluation}

Transplant recipients should contact their transplant center and be evaluated following return from travel if they develop new symptoms of infection. Workup and investigations will depend on evaluation of symptoms and timing of onset, as well as travel history with specific attention paid to destinations, activities, and exposures. In general, travelers who are well on return do not need to be seen after foreign travel. However, if they have been in high-risk situations or have a known or potential exposure to infection, then evaluation for necessary screening should be pursued. Examples of such may include working or volunteering in a healthcare setting, exposure to blood-borne pathogen, new sexual partner(s), etc.

\section{Conclusion}

Travel is an important component of many people's lives, whether it is for business, visiting friends and relatives, or leisure purposes. In 2017, the United Nations World Travel Organization documented 1.326 billion international tourist arrivals worldwide [157]. This number is expected to continue to increase. Among those traveling to international destinations include transplant recipients, who are immunosuppressed and at increased risk of infection. Transplant recipients should 
be counseled on the importance of pre-departure travel assessment when planning trips abroad, especially to areas of higher infection risk. They should seek medical advice before departure, and risk mitigation will depend on destination(s) and trip itineraries and should be tailored to the patients taking into consideration time since transplant, type of transplant, and immunosuppressive therapy.

\section{Key Points}

- Importance of safe travel should be discussed during the pretransplant evaluation.

- All transplant recipients should be seen by a travel medicine specialist prior to travel to regions with higher rates of infection.

- SOT patients should not travel to areas with higher infection risk during the first year posttransplant and/or during times of increased immunosuppression.

- HSCT patients should not travel to areas with higher infection risk during the first 3-12 months posttransplant depending on the transplant type and/or during times of increased immunosuppression and/or presence of GVHD.

- Travel recommendations, immunizations, and prophylaxis depend on destination and itinerary. Country-specific recommendations should be followed.

- Vaccine-preventable illnesses:

- Patients should be up to date with routine immunizations:

- Travel-related immunizations depend on travel destination.

- Live vaccines are contraindicated in SOT recipients.

- Live vaccines are contraindicated in HSCT recipients until 24 months posttransplant, no active GVHD, and they are no longer taking immunosuppressive therapy:

- Patients traveling to countries with yellow fever immunization requirements should travel with an official waiver.

- Prophylaxis:

- Necessary prophylaxis should be assessed by trip destination and itinerary.

- One of the most important and common infections that requires prophylaxis when traveling is malaria.

- Malaria prophylaxis should be based on country-specific guidelines.

- Assess for drug interactions with immunosuppressant agents.

- Counseling:

- Topics including prevention of food- and water-borne illness, respiratory infections, insect-borne illnesses, blood-borne infections, and sexually transmitted infections should be covered during the pre-travel visit.

- Patients should travel with adequate supply of medications (especially immunosuppressants) and copies of prescriptions.

- Patients should be aware of transplant centers at which they could seek medical attention if they become ill while away.

- Patients should have adequate travel medical insurance.

- Patients should be aware to seek medical attention if they develop signs and symptoms of infection upon return home after travel. 


\section{References}

1. Kotton CN, Hibberd PL. Travel medicine and transplant tourism in solid organ transplantation. Am J Transplant. 2013;13(s4):337-47. https://doi.org/10.1111/ajt.12125.

2. Human Organ and Tissue Transplantation. 2004. https://www.who.int/transplantation/en/ A57_R18-en.pdf. Accessed 25 Feb 2019.

3. Participants in the International Summit on Transplant Tourism and Organ Trafficking Convened by the Transplantation Society and International Society of Nephrology in Istanbul, Turkey, April 30-May 2, 2008. The declaration of Istanbul on organ trafficking and transplant tourism. Transplantation. 2008;86(8):1013-8. https://doi.org/10.1097/TP.0b013e318185ffc9.

4. The Declaration of Istanbul on Organ Trafficking and Transplant Tourism (2018 Edition). 2018. https://www.declarationofistanbul.org/images/Policy_Documents/2018_Ed_Do/2018 Edition_of the_Declaration_of_Istanbul_Final.pdf. Accessed 30 July 2018.

5. Caulfield T, Zarzeczny A. Curbing transplant tourism: Canadian physicians and the law. CMAJ. 2016;188(13):935-6. https://doi.org/10.1503/cmaj.160497.

6. WHO | WHO proposes global agenda on transplantation. WHO. 2010. http://www.who.int/ mediacentre/news/releases/2007/pr12/en/. Accessed 1 Aug 2018.

7. Prasad GVR, Shukla A, Huang M, D'A Honey RJ, Zaltzman JS. Outcomes of commercial renal transplantation: a Canadian experience. Transplantation. 2006;82(9):1130-5. https://doi. org/10.1097/01.tp.0000241072.03400.11.

8. Prasad GVR, Ananth S, Palepu S, Huang M, Nash MM, Zaltzman JS. Commercial kidney transplantation is an important risk factor in long-term kidney allograft survival. Kidney Int. 2016;89(5):1119-24. https://doi.org/10.1016/j.kint.2015.12.047.

9. Geddes CC, Henderson A, Mackenzie P, Rodger SC. Outcome of patients from the west of Scotland traveling to Pakistan for living donor kidney transplants. Transplantation. 2008;86 (8):1143-5. https://doi.org/10.1097/TP.0b013e318187cdd0.

10. Gill J, Madhira BR, Gjertson D, et al. Transplant tourism in the United States: a single-center experience. Clin J Am Soc Nephrol. 2008;3(6):1820-8. https://doi.org/10.2215/ CJN.02180508.

11. Cha R-H, Kim YC, Oh YJ, et al. Long-term outcomes of kidney allografts obtained by transplant tourism: observations from a single center in Korea. Nephrology. 2011;16 (7):672-9. https://doi.org/10.1111/j.1440-1797.2011.01480.x.

12. Babik JM, Chin-Hong P. Transplant tourism: understanding the risks. Curr Infect Dis Rep. 2015;17(4):18. https://doi.org/10.1007/s11908-015-0473-x.

13. Quach K, Sultan H, Li Y, Famure O, Kim SJ. Outcomes of kidney transplantation abroad. Prog Transplant. 2016;26(1):5-12. https://doi.org/10.1177/1526924816632133.

14. American Society for Transplantation and Cellular Therapy. Stem cell therapy and medical tourism - American Society for Transplantation and Cellular Therapy. https://www.asbmt.org/ practice-resources/policy-statements/stem-cell-therapy-and-medical-tourism. Accessed 7 Oct 2019.

15. Buchan CA, Kotton CN. Travel medicine, transplant tourism, and the solid organ transplant recipient - guidelines from the American Society of Transplantation Infectious Diseases Community of Practice. Clin Transpl. 2019;33(9):e13529. https://doi.org/10.1111/ctr.13529.

16. Kennedy SE, Shen Y, Charlesworth JA, et al. Outcome of overseas commercial kidney transplantation: an Australian perspective. Med J Aust. 2005;182(5):224-7. http://www.ncbi. nlm.nih.gov/pubmed/15748132. Accessed 30 July 2018

17. Sever MŞ, Kazancioğlu R, Yildiz A, et al. Outcome of living unrelated (commercial) renal transplantation. Kidney Int. 2001;60(4):1477-83. https://doi.org/10.1046/j.15231755.2001.00951.x.

18. Chen LH, Wilson ME. The globalization of healthcare: implications of medical tourism for the infectious disease clinician. Clin Infect Dis. 2013;57(12):1752-9. https://oi.org/10.1093/cid/ cit540. 
19. Merion RM, Barnes $\mathrm{AD}$, Lin $\mathrm{M}$, et al. Transplants in foreign countries among patients removed from the US transplant waiting list. Am J Transplant. 2008;8(4p2):988-96. https:// doi.org/10.1111/j.1600-6143.2008.02176.x.

20. Gill J, Diec O, Landsberg DN, et al. Opportunities to deter transplant tourism exist before referral for transplantation and during the workup and management of transplant candidates. Kidney Int. 2011;79(9):1026-31. https://doi.org/10.1038/ki.2010.540.

21. Martín-Dávila P, Fortún J, López-Vélez R, et al. Transmission of tropical and geographically restricted infections during solid-organ transplantation. Clin Microbiol Rev. 2008;21 (1):60-96. https://doi.org/10.1128/CMR.00021-07.

22. Marks PW, Witten CM, Califf RM. Clarifying stem-cell therapy's benefits and risks. N Engl J Med. 2017;376(11):1007-9. https://doi.org/10.1056/NEJMp1613723.

23. Caulfield T, Zarzeczny A, Toronto Stem Cell Working Group TSCW. Stem cell tourism and Canadian family physicians. Can Fam Physician. 2012;58(4):365-8, e182-5. http://www.ncbi. nlm.nih.gov/pubmed/22611603. Accessed 7 Oct 2019

24. FDA | FDA warns about stem cell therapies. https://www.fda.gov/consumers/consumerupdates/fda-warns-about-stem-cell-therapies. Accessed 3 Dec 2019.

25. Boggild AK, Sano M, Humar A, Gilman M, Salit I, Kain KC. Travel patterns and risk behavior in solid organ transplant recipients. J Travel Med. 2004;11:37-43.

26. Hochberg NS, Barnett ED, Chen LH, et al. International travel by persons with medical. Mayo Clin Proc. 2013;88(11):1231-40. https://doi.org/10.1016/j.mayocp.2013.07.018.

27. Roukens AHE, van Dissel JT, de Fijter JW, Visser LG. Health preparations and travel-related morbidity of kidney transplant recipients traveling to developing countries. Clin Transpl. 2007;21(4):567-70. https://doi.org/10.1111/j.1399-0012.2007.00691.x.

28. Mikati T, Griffin K, Lane D, Matasar M, Shah MK. International travel patterns and travel risks for stem cell transplant recipients. J Travel Med. 2015;22(1):39-47. https://doi.org/10.1111/ jtm. 12166.

29. Tomblyn M, Chiller T, Einsele H, et al. Guidelines for preventing infectious complications among hematopoietic cell transplant recipients: a global perspective recommendations. Biol Blood Marrow Transplant. 2009;15(10):1143-238. https://doi.org/10.1016/j. bbmt.2009.06.019.Guidelines.

30. WHO | Fact Sheet: Influenza (Seasonal). https://www.who.int/en/news-room/fact-sheets/ detail/influenza-(seasonal). Accessed 7 Apr 2019.

31. Ison MG. Influenza prevention and treatment in transplant recipients and immunocompromised hosts. Influenza Other Respir Viruses. 2013;7:60-6. https://doi.org/10.1111/irv.12170.

32. Engelhard D, Mohty B, de la Camara R, Cordonnier C, Ljungman P. European guidelines for prevention and management of influenza in hematopoietic stem cell transplantation and leukemia patients: summary of ECIL-4 (2011), on behalf of ECIL, a joint venture of EBMT, EORTC, ICHS, and ELN. Transpl Infect Dis. 2013;15(3):219-32. https://doi.org/10.1111/ tid.12054.

33. Goeijenbier M, van Genderen P, Ward BJ, Wilder-Smith A, Steffen R, Osterhaus ADME. Travellers and influenza: risks and prevention. J Travel Med. 2017;24(1) https://doi.org/ 10.1093/jtm/taw078.

34. Boggild AK, Castelli F, Gautret P, et al. Latitudinal patterns of travel among returned travelers with influenza: results from the GeoSentinel Surveillance Network, 1997-2007. J Travel Med. 2012;19(1):4-8. https://doi.org/10.1111/j.1708-8305.2011.00579.x.

35. Hirve $\mathrm{S}$, Newman LP, Paget J, et al. Influenza seasonality in the tropics and subtropics - when to vaccinate? PLoS One. 2016;11(4):e0153003. https://doi.org/10.1371/journal. pone. 0153003 .

36. WHO | International travel and health: Seasonal influenza. http://www.who.int/ith/vaccines/ seasonal_influenza/en/. Accessed 30 July 2018.

37. WHO | Fact Sheets: Measles. WHO. http://www.who.int/en/news-room/fact-sheets/detail/mea sles. Accessed 25 Mar 2019. 
38. Measles in Europe: record number of both sick and immunized. February 2019. http://www. euro.who.int/en/media-centre/sections/press-releases/2019/measles-in-europe-record-num ber-of-both-sick-and-immunized. Accessed 25 Mar 2019.

39. Avery RK, Ljungman P. Prophylactic measures in the solid-organ recipient before transplantation. Clin Infect Dis. 2001;33(s1):S15-21. https://doi.org/10.1086/320899.

40. Molrine DC, Hibberd PL. Vaccines for transplant recipients. Infect Dis Clin N Am. 2001;15 (1):273-305. https://doi.org/10.1016/S0891-5520(05)70279-8.

41. Duchini A, Goss JA, Karpen S, Pockros PJ. Vaccinations for adult solid-organ transplant recipients: current recommendations and protocols. Clin Microbiol Rev. 2003;16(3):357-64. https://doi.org/10.1128/CMR.16.3.357-364.2003.

42. Chong PP, Avery RK. A comprehensive review of immunization practices in solid organ transplant and hematopoietic stem cell transplant recipients. Clin Ther. 2017;39(8):1581-98. https://doi.org/10.1016/j.clinthera.2017.07.005.

43. Kotton CN, Kroger AT, Feedman D. Immunocompromised travelers - Chapter 8 - 2018 Yellow Book | Travelers' Health | CDC. https://wwwnc.cdc.gov/travel/yellowbook/2018/ advising-travelers-with-specific-needs/immunocompromised-travelers. Published 2017. Accessed 30 July 2018.

44. Danziger-Isakov L, Kumar D, the AST Infectious Diseases Community of Practice. Vaccination in solid organ transplantation. Am J Transplant. 2013;13(s4):311-7. https://doi. org/10.1111/ajt.12122.

45. Ljungman $\mathrm{P}$, Cordonnier $\mathrm{C}$, Einsele $\mathrm{H}$, et al. Vaccination of hematopoietic cell transplant recipients. Bone Marrow Transplant. 2009;44(8):521-6. https://doi.org/10.1038/ bmt.2009.263.

46. Carpenter PA, Englund JA. How I vaccinate blood and marrow transplant recipients. Blood. 2016;127(23):2824-32. https://doi.org/10.1182/blood-2015-12-550475.

47. L'Huillier AG, Kumar D. Immunizations in solid organ and hematopoeitic stem cell transplant patients: a comprehensive review. Hum Vaccin Immunother. 2015;11 (12):2852-63. https://doi.org/10.1080/21645515.2015.1078043.

48. WHO | Fact Sheet: Middle East respiratory syndrome coronavirus (MERS-CoV). https://www. who.int/news-room/fact-sheets/detail/middle-east-respiratory-syndrome-coronavirus-(merscov). Accessed 30 Mar 2019.

49. Watson JT, Gerber SI. Middle East Respiratory Syndrome (MERS) - Chapter 3 - 2018 Yellow Book | Travelers' Health | CDC. https://wwwnc.cdc.gov/travel/yellowbook/2018/infectiousdiseases-related-to-travel/middle-east-respiratory-syndrome-mers. Accessed 30 Mar 2019.

50. AlGhamdi M, Mushtaq F, Awn N, Shalhoub S. MERS CoV infection in two renal transplant recipients: case report. Am J Transplant. 2015;15(4):1101-4. https://doi.org/ 10.1111/ajt.13085.

51. Motabi IH, Zaidi SZA, Ibrahim MH, et al. Report of Middle East Respiratory Syndrome Coronavirus (MERS-CoV) infection in four patients with hematological malignancies treated at King Fahad Medical City, Riyadh, Saudi Arabia. Blood. 2016;128(22):4903. http://www. bloodjournal.org/content/128/22/4903. Accessed 21 Sept 2019

52. Hall AJ, Lopman B. Norovirus - Chapter 3 - 2018 Yellow Book | Travelers' Health | CDC. https:/wwwnc.cdc.gov/travel/yellowbook/2018/infectious-diseases-related-to-travel/ norovirus. Accessed 8 Apr 2019.

53. Rosen J. Travel medicine and the solid organ transplant recipient. Infect Dis Clin NA. 2013;27 (2):429-57. https://doi.org/10.1016/j.idc.2013.02.009.

54. Bok K, Green KY. Norovirus gastroenteritis in immunocompromised patients. N Engl J Med. 2013;368(10) https://doi.org/10.1056/NEJMc1301022.

55. WHO | Fact Sheet: Hepatitis A. https://www.who.int/news-room/fact-sheets/detail/hepatitis-a. Accessed 25 Mar 2019.

56. Ryan ET, Kain KC. Health advice and immunizations for travelers. N Engl J Med. 2000;342 (23):1716-25. https://doi.org/10.1056/NEJM200006083422306. 
57. Nelson NP. Hepatitis A - Chapter 3 - 2018 Yellow Book | Traveler's Health | CDC. https:// wwwnc.cdc.gov/travel/yellowbook/2018/infectious-diseases-related-to-travel/hepatitis-a. Published 2017. Accessed 21 Sept 2018.

58. Jeon HJ, Ro H, Jeong JC, et al. Efficacy and safety of hepatitis A vaccination in kidney transplant recipients. Transpl Infect Dis. 2014;16(3):511-5. https://doi.org/10.1111/tid.12217.

59. Nelson NP. Updated dosing instructions for immune globulin (human) GamaSTAN S/D for hepatitis A virus prophylaxis. MMWR Morb Mortal Wkly Rep. 2017;66(36):959-60. https:// doi.org/10.15585/mmwr.mm6636a5.

60. Te H, Doucette K. Viral hepatitis: guidelines by the American Society of Transplantation Infectious Disease Community of Practice. Clin Transpl. 2019;33(9):e13514. https://doi.org/ $10.1111 /$ ctr.13514.

61. WHO | Fact Sheet: Hepatitis B. https://www.who.int/news-room/fact-sheets/detail/hepatitis-b. Accessed 25 Mar 2019.

62. Canadian Immunization Guide: Part 3: Vaccination of specific populations. Immunization of immunocompromised persons. https://www.canada.ca/en/public-health/services/publications/ healthy-living/canadian-immunization-guide-part-3-vaccination-specific-populations/page-8immunization-immunocompromised-persons.html. Published 2017. Accessed 31 May 2017.

63. WHO | Fact sheet: Hepatitis E. https://www.who.int/news-room/fact-sheets/detail/hepatitis-e. Accessed 25 March 2019.

64. Hepatitis E - Chapter 3 - 2018 Yellow Book | Travelers' Health | CDC. https://wwwnc.cdc. gov/travel/yellowbook/2018/infectious-diseases-related-to-travel/hepatitis-e. Accessed 25 Mar 2019.

65. WHO | Fact Sheet: Poliomyelitis. https://www.who.int/news-room/fact-sheets/detail/poliomy elitis. Accessed 25 Mar 2019.

66. Global Polio Eradication Initiative - Endemic Countries. http://polioeradication.org/wherewe-work/polio-endemic-countries/. Accessed 30 July 2018.

67. Brandão LGP, Santoro-Lopes G, Oliveira S de S, da Silva EE, do Brasil PEAA. Seroprevalence of antibodies against the three serotypes of poliovirus and IPV vaccine response in adult solid organ transplant candidates. Vaccine. 2018;36(31):4681-6. https:// doi.org/10.1016/J.VACCINE.2018.06.031.

68. Brandão LGP, do Brasil PEAA, Oliveira S de S, da SEE, Lopes GS. Seronegativity to polio viruses among previously immunized adult candidates to solid organ transplantation. Braz J Infect Dis. 2018;22(2):150-2. https://doi.org/10.1016/J.BJID.2018.02.003.

69. CDC | Global Health - Newsroom - Yellow Fever. https://www.cdc.gov/globalhealth/news room/topics/yellowfever/index.html. Published 2018. Accessed 30 July 2018.

70. WHO | Fact Sheet - Yellow Fever. http://www.who.int/news-room/fact-sheets/detail/yellowfever. Accessed 30 July 2018.

71. Fishman JA. Smallpox and live-virus vaccination in transplant recipients. Am J Transplant. 2003;3(7):786-93. https://doi.org/10.1034/j.1600-6143.2003.00145.x.

72. Kotton CN, Ryan ET, Fishman JA. Prevention of infection in adult travelers after solid organ transplantation. Am J Transplant. 2005;5(1):8-14. https://doi.org/10.1111/j.16006143.2004.00708.x.

73. Staples J, Gershman M, Fischer M. Yellow fever vaccine recommendations of the Advisory Committee on Immunization Practices (ACIP). MMWR Recomm Rep. 2010;59 No. RR7:1-27. www.cdc.gov/mmwr. Accessed 30 July 2018.

74. Wyplosz B, Burdet C, Fran H. Persistence of yellow fever vaccine - induced antibodies after solid organ transplantation. Am J Transplant. 2013;13:2458-61. https://doi.org/10.1111/ ajt.12338.

75. Gershman M, Staples J. Yellow Fever - Chapter 3 - 2018 Yellow Book | Travelers' Health | CDC. https://wwwnc.cdc.gov/travel/yellowbook/2018/infectious-diseases-related-to-travel/ yellow-fever. Published 2018. Accessed 30 July 2018.

76. Sicre de Fontbrune F, Arnaud C, Cheminant M, et al. Immunogenicity and safety of yellow fever vaccine in allogeneic hematopoietic stem cell transplant recipients after withdrawal of 
immunosuppressive therapy. J Infect Dis. 2018;217(3):494-7. https://doi.org/10.1093/infdis/ jix564.

77. Canadian Immunization Guide: Part 4: Active vaccines: Japanese encephalitis vaccine. https:// www.canada.ca/en/public-health/services/publications/healthy-living/canadian-immuniza tion-guide-part-4-active-vaccines/page-11-japanese-encephalitis-vaccine.html. Accessed 2 Aug 2018.

78. Hills, S.L; Rabe, I.BF; Fischer M. Japanese encephalitis - Chapter 3 - 2018 Yellow Book Travelers' Health | CDC. https://wwwnc.cdc.gov/travel/yellowbook/2018/infectious-diseasesrelated-to-travel/japanese-encephalitis. Published 2018. Accessed 30 July 2018.

79. Fischer M, Lindsey N, Staples JE, Hills S, Centers for Disease Control and Prevention (CDC). Japanese encephalitis vaccines: recommendations of the Advisory Committee on Immunization Practices (ACIP). MMWR Recomm Rep Morb Mortal Wkly Rep Recomm Rep. 2010;59 (RR-1):1-27. http://www.ncbi.nlm.nih.gov/pubmed/20224546. Accessed 30 July 2018

80. Trubiano JA, Johnson D, Sohail A, Torresi J. Travel vaccination recommendations and endemic infection risks in solid organ transplantation recipients. J Travel Med. 2016;23 (6):1-15. https://doi.org/10.1093/jtm/taw058.

81. Darrigo LG, de Sant'Anna Carvalho AM, Machado CM. Chikungunya, Dengue, and Zika in immunocompromised hosts. Curr Infect Dis Rep. 2018;20(4):5. https://doi.org/10.1007/ s11908-018-0612-2.

82. Clemente WT, Pierrotti LC, Abdala E, et al. Recommendations for management of endemic diseases and travel medicine in solid-organ transplant recipients and donors. Transplantation. 2018;102(2):193-208. https://doi.org/10.1097/TP.0000000000002027.

83. Mourão PHO, Gavalda J, Salvador F, Molina I. Recommendations for management of endemic diseases and travel medicine in solid-organ transplant recipients and donors. Transplantation. 2018;102(2S Suppl 2):S81. https://doi.org/10.1097/TP.0000000000002031.

84. Morris MI, Grossi P, Nogueira ML, Azevedo LS. Arboviruses recommendations for solid-organ transplant recipients and donors. Transplantation. 2018;102:S42-51. https://doi. org/10.1097/TP.0000000000002011.

85. Fernandes PFCBC, Siqueira RA, Girão ES, et al. Dengue in renal transplant recipients: clinical course and impact on renal function. World J Transplant. 2017;7(1):57. https://doi.org/ 10.5500/wjt.v7.i1.57.

86. Costa SD, da Silva GB, Jacinto CN, et al. Dengue fever among renal transplant recipients: a series of 10 cases in a tropical country. Am J Trop Med Hyg. 2015;93(2):394-6. https://doi. org/10.4269/ajtmh.15-0038.

87. Prasad N, Bhadauria D, Sharma RK, Gupta A, Kaul A, Srivastava A. Dengue virus infection in renal allograft recipients: a case series during 2010 outbreak. Transpl Infect Dis. 2012;14 (2):163-8. https://doi.org/10.1111/j.1399-3062.2011.00699.x.

88. Nasim A, Anis S, Baqi S, Akhtar SF, Baig-Ansari N. Clinical presentation and outcome of dengue viral infection in live-related renal transplant recipients in Karachi. Pakistan Transpl Infect Dis. 2013;15:516-25. https://doi.org/10.1111/tid.12114.

89. de Souza Pereira BB, Darrigo Junior LG, de Mello Costa TC, et al. Prolonged viremia in dengue virus infection in hematopoietic stem cell transplant recipients and patients with hematological malignancies. Transpl Infect Dis. 2017;19(4):e12721. https://doi.org/10.1111/ tid.12721.

90. Machado CM, Pereira BB de S, Felix AC, et al. Zika and chikungunya virus infections in hematopoietic stem cell transplant recipients and oncohematological patients. Blood Adv. 2017;1(10):624-7. https://doi.org/10.1182/bloodadvances.2016003285.

91. Girão ES, Santos BGR, Amaral ES, et al. Chikungunya infection in solid organ transplant recipients. Transplant Proc. 2017;49(9):2076-81. https://doi.org/10.1016/j. transproceed.2017.07.004.

92. Zika Virus |CDC. https://www.cdc.gov/zika/index.html. Accessed 13 Sept 2018.

93. Polen KD, Gilboa SM, Hills S, et al. Update: interim guidance for preconception counseling and prevention of sexual transmission of Zika virus for men with possible Zika virus 
exposure - United States, August 2018. MMWR Morb Mortal Wkly Rep. 2018;67 (31):868-71. https://doi.org/10.15585/mmwr.mm6731e2.

94. Nogueira ML, Estofolete CF. Zika virus infection and solid organ transplantation: a new challenge. Am J Transpl. 2017;17(3):791-5. https://doi.org/10.1111/ajt.14047.

95. Kotton CN. Zika virus and solid organ transplantation. Transplantation. 2016;100(5):970-2. https://doi.org/10.1097/TP.0000000000001179.

96. Wallace MW, Peterson BW, Shlim DR. Rabies - Chapter 3 - 2018 Yellow Book | travelers' health | CDC. https://wwwnc.cdc.gov/travel/yellowbook/2018/infectious-diseases-related-totravel/rabies. Accessed 25 Mar 2019.

97. WHO | Rabies vaccines: WHO position paper - April 2018. WHO. 2018;16(93):201-220. http://www.who.int/rabies/resources/who_wer9316/en/. Accessed 30 July 2018.

98. Gibbons RV, Rupprecht CE. Postexposure rabies prophylaxis in immunosuppressed patients. JAMA. 2001;285(12):1574-5. http://www.ncbi.nlm.nih.gov/pubmed/11268256. Accessed 30 July 2018

99. WHO | Typhoid. WHO. 2018. https://www.who.int/mediacentre/factsheets/typhoid/en/. Accessed 26 Mar 2019.

100. Kotton CN. Travel and transplantation. Curr Opin Organ Transplant. 2012; p 1. https://doi.org/ 10.1097/MOT.0b013e328359266b.

101. Judd MC, Mintz ED. Typhoid \& Paratyphoid fever - chapter 3 - 2018 yellow book | travelers' health | CDC. https://wwwnc.cdc.gov/travel/yellowbook/2018/infectious-diseases-related-totravel/typhoid-paratyphoid-fever. Accessed 26 Mar 2019.

102. Wong KK, Burdette E, Mintz ED. Cholera - chapter 3 - 2018 yellow book | travelers' health | CDC. https://wwwnc.cdc.gov/travel/yellowbook/2018/infectious-diseases-related-to-travel/ cholera. Accessed 27 Mar 2019.

103. Canadian Immunization Guide: Part 4: Active Vaccines: Cholera and Enterotoxigenic Escherichia Coli (ETEC) Travellers' Diarrhea Vaccine. https://www.canada.ca/en/publichealth/services/publications/healthy-living/canadian-immunization-guide-part-4-active-vac cines/page-3-cholera-enterotoxigenic-escherichia-coli-travellers-diarrhea-vaccine.html. Published 2017. Accessed 30 July 2018.

104. Ahmed T, Bhuiyan TR, Zaman K, Sinclair D, Qadri F. Vaccines for preventing enterotoxigenic Escherichia coli (ETEC) diarrhoea. Cochrane Database Syst Rev. 2013;7:CD009029. https://doi.org/10.1002/14651858.CD009029.pub2.

105. Hill DR, Ericsson CD, Pearson RD, et al. The practice of travel medicine: guidelines by the Infectious Diseases Society of America. Clin Infect Dis. 2006;43(12):1499-539. https://doi. org $/ 10.1086 / 508782$.

106. Committee to Advise on Tropical Medicine and Travel (CATMAT). An Advisory Committee Statement (ACS): Statement on Travellers' Diarrhea. Public Health Agency of Canada. https:// www.canada.ca/en/public-health/services/travel-health/about-catmat/statement-travellers-diar rhea.html. Published 2015. Accessed 9 Aug 2018.

107. Global Task Force on Cholera Control (GTFCC). WHO | the use of oral cholera vaccines for international workers and travelers to and from cholera-affected countries; 2016. http://www. who.int/cholera/vaccines/OCV_use_International_Workers_Travelers_Technical_Note.pdf. Accessed 9 Aug 2018.

108. Connor BA. Travelers' Diarrhea - Chapter 2-2018 Yellow Book | Travelers' Health | CDC. https://wwwnc.cdc.gov/travel/yellowbook/2018/the-pre-travel-consultation/travelers-diar rhea. Accessed 27 Mar 2019.

109. O’Reilly CE, Iwamoto M, Griffin PM. Escherichia coli, diarrheagenic - Chapter 3 - 2018 Yellow Book | Travelers' Health | CDC. https://wwwnc.cdc.gov/travel/yellowbook/2018/infec tious-diseases-related-to-travel/escherichia-coli-diarrheagenic\#5166. Accessed 27 Mar 2019.

110. MacNeil JR, Meyer SA. CDC | Meningococcal Disease - Chapter 3 - 2018 Yellow Book | Travelers' Health. https://wwwnc.cdc.gov/travel/yellowbook/2018/infectious-diseasesrelated-to-travel/meningococcal-disease. Published 2017. Accessed 1 Aug 2018. 
111. Lessa FC. Pneumococcal Disease - Chapter 3 - 2018 Yellow Book | Travelers' Health |CDC. https://wwwnc.cdc.gov/travel/yellowbook/2018/infectious-diseases-related-to-travel/pneumo coccal-disease. Accessed 27 Mar 2019.

112. Tiwari TS. Tetanus - Chapter 3 - 2018 Yellow Book| Travelers' Health $\mid$ CDC. https://wwwnc. cdc.gov/travel/yellowbook/2018/infectious-diseases-related-to-travel/tetanus. Accessed 28 Mar 2019.

113. von Konig C-HW. Use of antibiotics in the prevention and treatment of Pertussis. Pediatr Infect Dis J. 2005;24(Supplement):S66-8. https://doi.org/10.1097/01.inf.0000160916.47479.22.

114. CDC | Combined Recommended Immunization Schedule for Adults Aged 19 Years or Older, United States. 2018. https://doi.org/10.7326/M17-3439.

115. TUBERCULOSIS Global Tuberculosis Report 2018; 2018. www.who.int/tb. Accessed 28 Mar 2019.

116. Subramanian AK, Theodoropoulos NM. Mycobacterium tuberculosis infections in solid organ transplantation: guidelines from the infectious diseases community of practice of the American Society of Transplantation. Clin Transpl. 2019;33(9):e13513. https://doi.org/10.1111/ ctr. 13513 .

117. Lobue P. Tuberculosis - Chapter 3 - 2018 Yellow Book | Travelers' Health | CDC. https:// wwwnc.cdc.gov/travel/yellowbook/2018/infectious-diseases-related-to-travel/tuberculosis. Published 2017. Accessed 9 Oct 2018.

118. Shoham S, Dominguez EA. Emerging fungal infections in solid organ transplant recipients: guidelines of the American Society of Transplantation Infectious Diseases Community of Practice. Clin Transpl. 2019;33(9):e13525. https://doi.org/10.1111/ctr.13525.

119. Miller R, Assi M. Endemic fungal infections in solid organ transplantation. Am J Transplant. 2013;13(s4):250-61. https://doi.org/10.1111/ajt.12117.

120. Panackal AA, Hajjeh RA, Cetron MS, Warnock DW, Cetron MS, Warnock DW. Fungal infections among returning travelers. Clin Infect Dis. 2002;35(9):1088-95. https://doi.org/ $10.1086 / 344061$.

121. Lortholary O, Charlier C, Lebeaux D, Lecuit M, Consigny PH. Fungal infections in immunocompromised travelers. Clin Infect Dis. 2013;56(6):861-9. https://oi.org/10.1093/cid/cis935.

122. Rappo U, Beitler JR, Faulhaber JR, et al. Expanding the horizons of histoplasmosis: disseminated histoplasmosis in a renal transplant patient after a trip to Bangladesh. Transpl Infect Dis. 2010;12(2):155-60. https://doi.org/10.1111/j.1399-3062.2009.00466.x.

123. Hart J, Dyer JR, Clark BM, McLellan DG, Perera S, Ferrari P. Travel-related disseminated Penicillium marneffei infection in a renal transplant patient. Transpl Infect Dis. 2012;14 (4):434-9. https://doi.org/10.1111/j.1399-3062.2011.00700.x.

124. Types of Fungal Diseases | Fungal Diseases | CDC. https://www.cdc.gov/fungal/diseases/ index.html. Accessed 5 Apr 2019.

125. Boggild AK, Yohanna S, Keystone JS, Kain KC. Prospective analysis of parasitic infections in Canadian travelers and immigrants. J Travel Med. 2006;13(3):138-44. https://doi.org/10.1111/ j.1708-8305.2006.00032.x.

126. Schwartz BS, Mawhorter SD. Parasitic infections in solid organ transplantation. Am J Transplant. 2013;13(s4):280-303. https://doi.org/10.1111/ajt.12120.

127. La Hoz RM, Morris MI. Tissue and blood protozoa including toxoplasmosis, Chagas disease, Leishmaniasis, Babesia, Acanthamoeba, Balamuthia, and Naegleria in solid organ transplant recipients - guidelines from the Infectious Diseases Community of Practice of the American Society of Transplantation. Clin Transpl. 2019;33(9):e13546. https://doi.org/10.1111/ ctr.13546.

128. WHO | Fact Sheet: Malaria. https://www.who.int/news-room/fact-sheets/detail/malaria. Accessed 28 Mar 2019.

129. Pierrotti LC, Levi ME, Di Santi SM, Segurado AC, Petersen E. Malaria disease recommendations for solid organ transplant recipients and donors. Transplantation. 2018;102:S16-26. https://doi.org/10.1097/TP.0000000000002017. 
130. Arguin PM, Tan KR. CDC | malaria - chapter 3 - 2018 yellow book | travelers' health. https:// wwwnc.cdc.gov/travel/yellowbook/2018/infectious-diseases-related-to-travel $/ \mathrm{malaria}$. Published 2017. Accessed 30 July 2018.

131. WHO | Fact Sheet: Leishmaniasis. https://www.who.int/news-room/fact-sheets/detail/leish maniasis. Accessed 30 Mar 2019.

132. Clemente WT, Mourão PHO, Lopez-Medrano F, Schwartz BS, García-Donoso C, TorreCisneros J. Visceral and cutaneous leishmaniasis recommendations for solid organ transplant recipients and donors. Transplantation. 2018;102(2S Suppl 2):S8-S15. https://doi.org/ 10.1097/TP.0000000000002018.

133. Herwaldt BL, Magill AJ. Leishmaniasis, visceral - Chapter 3 - 2018 Yellow Book | Travelers' Health | CDC. https://wwwnc.cdc.gov/travel/yellowbook/2018/infectious-diseases-related-totravel/leishmaniasis-visceral. Accessed 30 Mar 2019.

134. WHO | Fact Sheet: Trypanosomiasis, human African (sleeping sickness). https://www.who.int/ news-room/fact-sheets/detail/trypanosomiasis-human-african-(sleeping-sickness). Accessed 30 Mar 2019.

135. WHO | Fact Sheet: Chagas disease (American trypanosomiasis). https://www.who.int/newsroom/fact-sheets/detail/chagas-disease-(american-trypanosomiasis). Accessed 30 Mar 2019.

136. Pierrotti LC, Carvalho NB, Amorin JP, Pascual J, Kotton CN, López-Vélez R. Chagas disease recommendations for solid-organ transplant recipients and donors. Transplantation. 2018;102: S1-7. https://doi.org/10.1097/TP.0000000000002019.

137. Montgomery S. Trypanosomiasis, American (Chagas Disease) - Chapter 3 - 2018 Yellow Book | Travelers' Health | CDC. https://wwwnc.cdc.gov/travel/yellowbook/2018/infectiousdiseases-related-to-travel/trypanosomiasis-american-chagas-disease. Accessed 30 Mar 2019.

138. Kotton CN, Lattes R. Parasitic infections in solid organ transplant recipients. Am J Transplant. 2009;9(SUPPL. 4) https://doi.org/10.1111/j.1600-6143.2009.02915.x.

139. Jarque I, Salavert M, Pemán J. Parasitic infections in hematopoietic stem cell transplantation. Mediterr J Hematol Infect Dis. 2016;8(1):e2016035. https://doi.org/10.4084/ MJHID.2016.035.

140. Lubin AS, Snydman DR, Miller KB. Persistent babesiosis in a stem cell transplant recipient. Leuk Res. 2011;35(6):e77-8. https://doi.org/10.1016/j.leukres.2010.11.029.

141. Abanyie F. Strongyloidiasis - Chapter 3 - 2018 Yellow Book | Travelers' Health | CDC. https://wwwnc.cdc.gov/travel/yellowbook/2018/infectious-diseases-related-to-travel/strongy loidiasis. Accessed 30 Mar 2019.

142. Camargo LFA, Kamar N, Gotuzzo E, Wright AJ. Schistosomiasis and Strongyloidiasis recommendations for solid-organ transplant recipients and donors. Transplantation. 2018;102:S27-34. https://doi.org/10.1097/TP.0000000000002016.

143. Montgomery S. Schistosomiasis - Chapter 3-2018 Yellow Book | Travelers' Health | CDC. https://wwwnc.cdc.gov/travel/yellowbook/2018/infectious-diseases-related-to-travel/schisto somiasis. Accessed 30 Mar 2019.

144. Table of Contents | 2018 Yellow Book | Travelers' Health | CDC. https://wwwnc.cdc.gov/ travel/yellowbook/2018/table-of-contents. Accessed 30 Mar 2019.

145. Fishman JA. Infection in solid-organ transplant recipients. N Engl J Med. 2007;357:2601-14. https://doi.org/10.1016/j.semnephrol.2007.03.006.

146. Tomblyn M, Chiller T, Einsele H, et al. Guidelines for preventing infectious complications among hematopoietic cell transplantation recipients: a global perspective. Biol Blood Marrow Transplant. 2009;15(10):1143-238. https://doi.org/10.1016/j.bbmt.2009.06.019.

147. Winter K. Travel Health Kits - Chapter $2-2018$ Yellow Book| Travelers' Health | CDC. https://wwwnc.cdc.gov/travel/yellowbook/2018/the-pre-travel-consultation/travel-health-kits. Published 2017. Accessed 31 Aug 2018.

148. Avery RK, Michaels M. Update on immunizations in solid organ transplant recipients: what clinicians need to know. Am J Transplant. 2008;8(1):9-14. https://doi.org/10.1111/j.16006143.2007.02051.x. 
149. Canadian Immunization Guide: Part 3: Vaccination of Specific Populations. https://www. canada.ca/en/public-health/services/publications/healthy-living/canadian-immunizationguide-part-3-vaccination-specific-populations.html. Accessed 7 Jan 2018.

150. Aung AK, Trubiano JA, Spelman DW. Travel risk assessment, advice and vaccinations in immunocompromised travellers (HIV, solid organ transplant and haematopoeitic stem cell transplant recipients ): a review. Travel Med Infect Dis. 2015;13:31-47. https://doi.org/ 10.1016/j.tmaid.2014.12.007.

151. Committee to Advise on Tropical Medicine and Travel (CATMAT). An Advisory Committee Statement (ACS): the immunocompromised traveller. Canada Commun Dis Rep. 2007;33 (ACS-4):1-24. https://www.canada.ca/content/dam/phac-aspc/migration/phac-aspc/publicat/ ccdr-rmtc/07pdf/acs33-04.pdf. Accessed 30 July 2018

152. Rubin LG, Levin MJ, Ljungman P, et al. 2013 IDSA clinical practice guideline for vaccination of the immunocompromised host. Clin Infect Dis. 2014;58(3):e44-e100. https://doi.org/ 10.1093/cid/cit684.

153. Griffin PM, Hlavsa MC, Yoder JS. Food and water precautions - Chapter $2-2018$ Yellow Book | Travelers' Health | CDC. https:/wwwnc.cdc.gov/travel/yellowbook/2018/the-pretravel-consultation/food-water-precautions. Published 2017. Accessed 1 Aug 2018.

154. Eat and drink safely - travel health and safety. Government of Canada. https://travel.gc.ca/ travelling/health-safety/food-water. Published 2018. Accessed 1 Aug 2018.

155. Beeching NJ, Carratalà J, Razonable RR, Oriol I, Vilela EG. Traveler's Diarrhea recommendations for solid organ transplant recipients and donors. Transplantation. 2018;102:S35-41. https://doi.org/10.1097/TP.0000000000002015.

156. Riddle MS, Connor BA, Beeching NJ, et al. Guidelines for the prevention and treatment of travelers ' diarrhea: a graded expert panel report. J Travel Med. 2018;24(Suppl 1):S63-80. https://doi.org/10.1093/jtm/tax026.

157. UNWTO Tourism Highlights. https://doi.org/10.18111/9789284419876. 